\title{
Methodologies for the Possible Integral Generation of Geopolymers Based on Copper Tailings
}

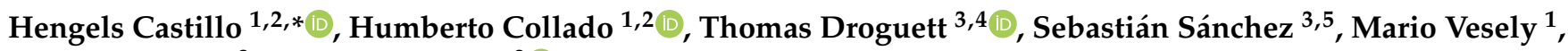 \\ Pamela Garrido ${ }^{3}$ and Sergio Palma ${ }^{2}$ (I)
}

1 JRI Ingeniería, Santiago 7770445, Chile; hcollado@jri.cl (H.C.); mvesely@jri.cl (M.V.)

2 Department of Metallurgical Engineering and Materials, Complex Fluids Laboratory, Universidad Técnica Federico Santa María, Santiago 8940572, Chile; sergio.palma@usm.cl

3 CIMS-JRI, Santiago 7850000, Chile; thomas.droguett@cimsjri.cl (T.D.); sebastian.sanchez@jri.cl (S.S.); pgarrido@cimsjri.cl (P.G.)

4 Department of Metallurgical Engineering, Universidad de Santiago de Chile, Santiago 9170022, Chile

5 Escuela de Ingeniería Química, Pontificia Universidad Católica de Valparaíso, Valparaíso 2340025, Chile

* Correspondence: hcastillo@jri.cl

check for

updates

Citation: Castillo, H.; Collado, H.; Droguett, T.; Sánchez, S.; Vesely, M.; Garrido, P.; Palma, S. Methodologies for the Possible Integral Generation of Geopolymers Based on Copper Tailings. Minerals 2021, 11, 1367. https://doi.org/10.3390/min11121367

Academic Editors: Thomas

N. Kerestedjian and

Alexander Karamanov

Received: 27 October 2021

Accepted: 23 November 2021

Published: 3 December 2021

Publisher's Note: MDPI stays neutral with regard to jurisdictional claims in published maps and institutional affiliations.

Copyright: (c) 2021 by the authors. Licensee MDPI, Basel, Switzerland. This article is an open access article distributed under the terms and conditions of the Creative Commons Attribution (CC BY) license (https:// creativecommons.org/licenses/by/ $4.0 /)$.

\begin{abstract}
It is of interest to study the use of copper tailings as a raw material to generate geopolymers due to the exorbitant amounts of existing tailings deposits, which also produce different risks to nearby communities. Therefore, using this industrial waste as construction material would result in several environmental and economic benefits. Due to the above, it is necessary to perform laboratory tests that account for the relevant variables to obtain fresh geopolymer pastes with good consistency, and to obtain hardened geopolymers with good mechanical strength. This report gives an account of the experimental work carried out in the laboratory of the CIMS Sustainable Mining Research Center of the Engineering Consulting Company JRI, exposing the preliminary results observed in the generation of geopolymers by means of seven different methods using copper tailings and $\mathrm{NaOH}$. Of the seven methods evaluated in the laboratory, it was observed that two of them deliver better results from a qualitative point of view, where the influence of the curing stage stands out, reflecting that temperature is one of the critical variables for the formation of geopolymers based on copper tailings and $\mathrm{NaOH}$. The best means to work the mixtures should be studied to optimize the solubility of the $\mathrm{NaOH}$ and, therefore, the dissolution of the aluminosilicates in the tailings.
\end{abstract}

Keywords: copper tailings geopolymers; geopolymer generation; mechanical strength; curing temperature

\section{Introduction}

The mining industry is the foundation for the manufacture of electronic communication equipment, machinery, aerospace materials, etc. In the process of refining valuable minerals, large amounts of mine tailings are produced. In China, approximately 10 billion tons of tailings were stored until 2009, with 1.5 billion tons of tailings being produced in 2011 alone [1]. Therefore, it is critical to develop procedures to address potential tailing-induced environmental pollution. Thus, there is great interest in the utilization of mine tailings, for which much energy is consumed during the comminution process, as construction materials using geopolymerization, a novel alkali-activation technique [2-5].

Geopolymerization is a process for obtaining a polymeric structure from aluminosilicate by dissolving aluminosilicate sources in a strong alkali (most commonly used is $\mathrm{NaOH}$ ) solution [6,7]. In addition to mine tailings, there are a variety of sources of aluminosilicates that can be used to produce geopolymers. The most common sources of aluminosilicates used for geopolymer production are metakaolin and by-products from other industries, such as fly ash, red muds, and slags. The geopolymer precursor materials must be rich in alumina $\left(\mathrm{Al}_{2} \mathrm{O}_{3}\right)$ and silica $\left(\mathrm{SiO}_{2}\right)$, preferably in amorphous reactive form [8], because these compounds are essential for the formation of the geopolymer gel, which is responsible for providing the geopolymer with rigidity and resistance. 
In addition to the aluminosilicate reagent, an alkaline activator is needed to produce the geopolymer. The alkaline activator causes the dissolution of the raw materials [9], and it must be carefully selected because its composition has different impacts on the properties of fresh geopolymer paste and development of the mechanical strength in the hardened geopolymers [10]. The process in which the aluminum and silicon present interact to form an amorphous solid structure is called polymerization, and this polymerization is favored by the application of moderate temperatures [2]. In the activation of the aluminosilicate source with $\mathrm{NaOH}$ (the most used alkaline reagent), the reaction starts with the dissolution of $\mathrm{Al}$ and $\mathrm{Si}$, which are precursor particles in the alkaline solution, and is then followed by polymerization in the aluminum-rich first gel phase, which will be transformed into silicon-rich final geopolymer gel [11]. The product resulting from the reaction between the aluminosilicate source and the alkaline activator is an amorphous substance composed of solid phases of aluminosilicates armed based on connections of $\mathrm{SiO}_{4}{ }^{4-}$ and $\mathrm{AlO}_{4}{ }^{5-}$ as tetrahedra forming a 3D structure.

The process of hardening the geopolymer is called curing, and this can be accomplished by the application of heat, or by simply leaving the geopolymer at ambient temperature if the composition of the geopolymer permits [12-14]. After curing for a specific time, the geopolymerization product shows greatly increased compressive strength. Therefore, the product can be used as construction materials such as bricks or road pavement material [15].

Geopolymers have been studied to a great extent as materials for construction $[4,16]$, being considered more environmentally friendly compared to the use of traditional Portland cement [17]. Geopolymeric blends use industrial waste to develop materials with properties similar to those of concrete [18]. The best known example of this reuse is the fly ash from coal-based power plants [19].

It is of interest to the CIMS Sustainable Mining Research Center of the Engineering Consulting Company JRI to study the use of copper tailings as raw material for the generation of geopolymers, in order to be able to use this technology as filling of underground stopes [20-23]. To achieve this purpose, the research team made a set of seven geopolymer mixtures to be made in the CIMS's labs to capture the predominant variables in the generation of geopolymer mixtures.

This report gives an account of the experimental work that was carried out and the preliminary results that were observed in its execution, focusing on the influence of the methodologies used in the laboratory.

\section{Materials and Methods}

\subsection{Materials}

The copper tailings used in this research come from the San Pedro mining company, located in the commune of Til Til, Chile, which, by means of a subway operation, obtains polymetallic copper and silver concentrates. The type of deposit from which these concentrates are extracted corresponds to a copper porphyry, where the main element of interest extracted is copper. The tailings obtained from this mine were filtered, obtaining a solids content of $\mathrm{Cp}=85.85 \%$ (Figure 1). Process water samples were taken to be used in the formation of geopolymers. 


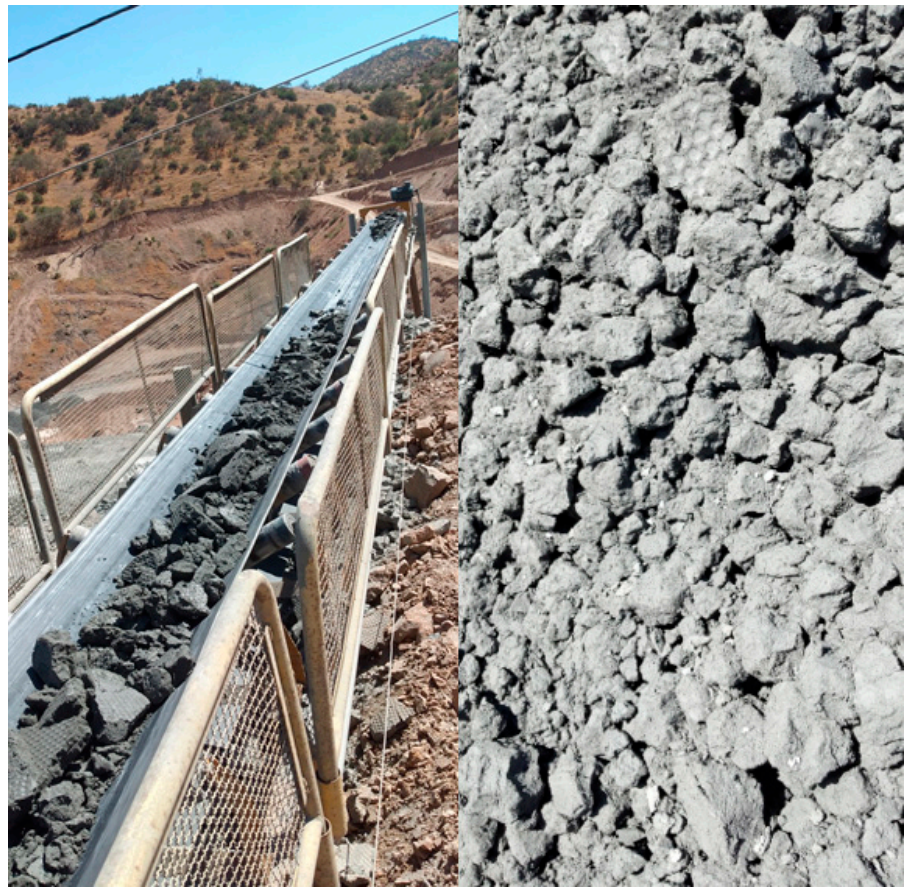

Figure 1. Filtered copper tailings in a mining company in Chile.

The XRD pattern of the copper tailings powder is shown in Figure 2. The copper tailings used in this research is mainly a crystalline material which is composed mostly of albite $\left(\mathrm{NaAlSi}_{3} \mathrm{O}_{8}\right)$, and to a lesser extent, clinochlore $\left(\mathrm{Mg}_{5} \mathrm{Al}\left(\mathrm{AlSi}_{3} \mathrm{O}_{10}\right)(\mathrm{OH})_{8}\right)$, quartz $\left(\mathrm{SiO}_{2}\right)$, epidote $\left(\mathrm{Ca}_{2}\left(\mathrm{Al}_{2}, \mathrm{Fe}\right)\left(\mathrm{SiO}_{4}\right)\left(\mathrm{Si}_{2} \mathrm{O}_{7}\right) \mathrm{O}(\mathrm{OH})\right)$, and orthoclase $\left(\mathrm{KAlSi}_{3} \mathrm{O}_{8}\right)$. The XRD analysis was carried out in the Geomaq Chile laboratory and all XRD data were collected using a D8 diffractometer of EE.UU. Data for the Rietveld refinement were collected on the Endeavor-Bruker geometry of $3^{\circ}$ to $70^{\circ}$ theta with an increase of $0.02 \%$ s and a step time of $0.2 \mathrm{~s}$.

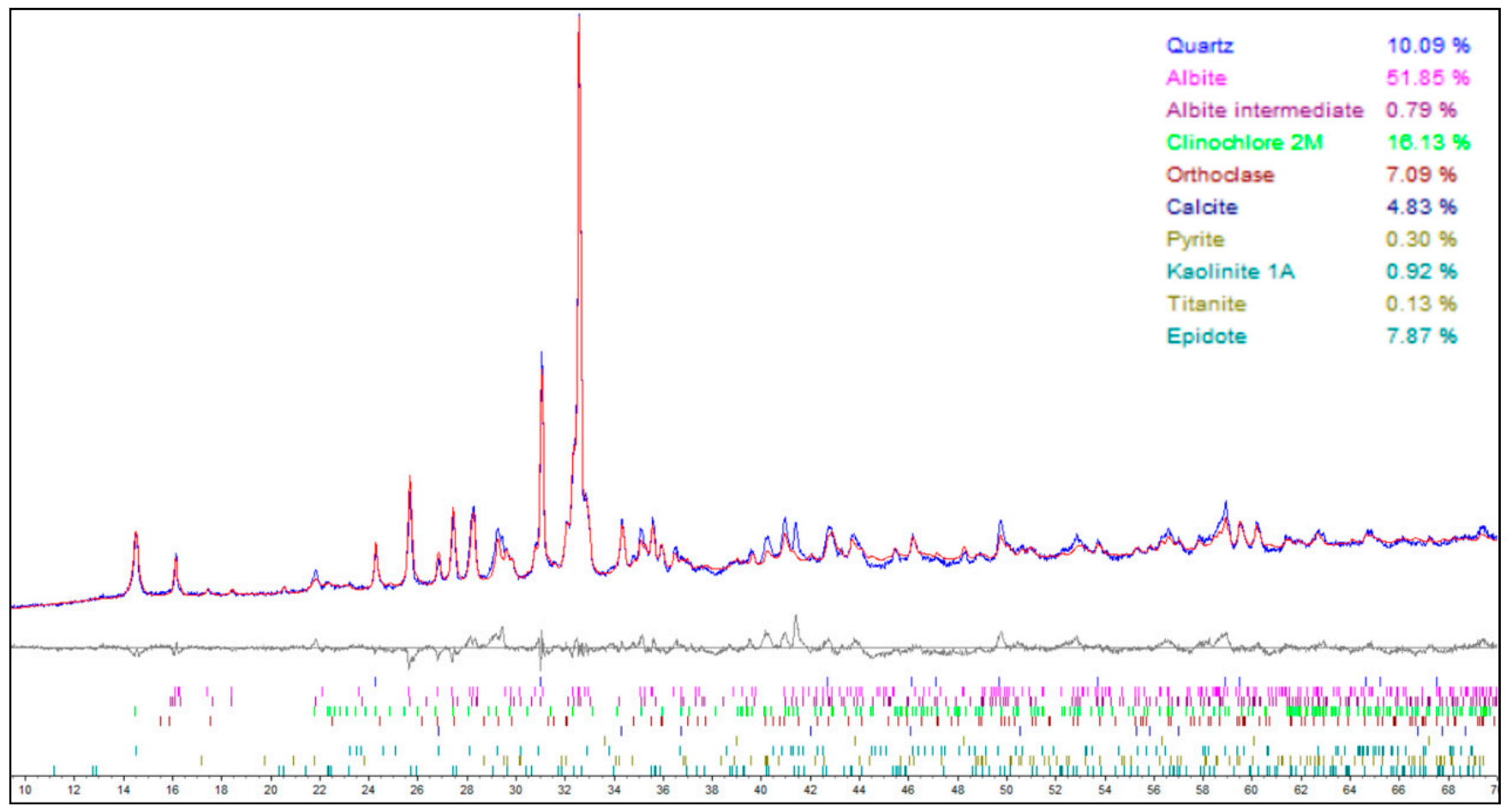

Figure 2. XRD pattern of un-reacted copper tailings. 
The tailings samples were homogenized by adding industrial water until reaching a $\mathrm{Cp}$ solids content of $70 \%$. After this, the tailings were filtered until they had a Cp of $83 \%$.

The characterization of the copper tailings used in this research was undertaken by means of the Inductive Coupling Plasma (ICP) test, where the results obtained correspond to the average values obtained in the analysis of several samples. The chemical composition of the tailings is presented in Table 1. The ICP analysis was performed under the ISO 17025.Of.2005 Accredited Method INN, LE1386, using an analytical balance with a minimum precision of $1 \mathrm{mg}$ to weigh the sample and prepare it for leaching at a temperature of $23 \pm 2{ }^{\circ} \mathrm{C}$, for $18 \pm 2 \mathrm{~h}$ at $30 \pm 2 \mathrm{rpm}$. Then the precipitation test is carried out for which a $20 \mathrm{~mL}$ extract is taken and $2 \mathrm{~mL}$ of $\mathrm{HNO}_{3}$ is added; if precipitation is observed, the rest of the extract is not acidified, and the measurement is obtained. If the extract does not present precipitation, it is acidified with $\mathrm{HNO}_{3}$ acid to $\mathrm{pH}=2$ and stored at $4{ }^{\circ} \mathrm{C}$, for later measurement. After this, $2.5 \mathrm{~mL}$ of the $20 \mathrm{~mL}$ extract is diluted and emptied into a $50 \mathrm{~mL}$ volumetric flask containing $12.5 \mathrm{~mL}$ of quenched aqua regia, to enable measurement by ICP-MS with an ICP-MS AURORA BRUKER, EE.UU., in the Andes Analytical Assay Laboratory: 3AAA in Chile.

Table 1. Tailings chemical characterization test (ICP).

\begin{tabular}{cccc}
\hline Element & Concentration [mg/L] & Element & Concentration [mg/L] \\
\hline $\mathrm{Si}$ & 26.95 & $\mathrm{~K}$ & 1.19 \\
$\mathrm{Al}$ & 9.50 & $\mathrm{Ti}$ & 0.60 \\
$\mathrm{Fe}$ & 8.05 & $\mathrm{Mn}$ & 0.25 \\
$\mathrm{Ca}$ & 3.28 & $\mathrm{~S}$ & 0.12 \\
$\mathrm{Na}$ & 2.67 & $\mathrm{Cr}$ & $<0.01$ \\
$\mathrm{Mg}$ & 2.10 & & \\
\hline
\end{tabular}

Due to the procedures for obtaining results by means of an ICP test, which consist of dehydrating the sample, atomizing it, exciting the atoms present, and finally ionizing them, which is achieved due to the high temperatures reached by the plasma, the samples may be affected by such procedures. This may have an effect on the results obtained. Because of this, caution should be exercised when using these data.

From the characterization of the tailings presented in Table 1, it is observed that the main element in the sample is silicon and, to a lesser extent, aluminum, and iron, being the first two fundamentals for geopolymer's synthesis [23-26].

The characterization of the industrial water used for the homogenization of the tailings was undertaken also by means of the Inductive Coupling Plasma (ICP) test, where, as in the case of the tailings, the results obtained correspond to the average values obtained from the analysis of several samples. These results are described in Table 2.

Table 2. ICP test for characterization of industrial water.

\begin{tabular}{cccc}
\hline Element & Concentration [mg/L] & Element & Concentration [mg/L] \\
\hline $\mathrm{S}$ & 215 & $\mathrm{Ta}$ & $<1.00$ \\
$\mathrm{~K}$ & 210 & $\mathrm{Th}$ & $<1.00$ \\
$\mathrm{Na}$ & 158 & $\mathrm{Tl}$ & $<1.00$ \\
$\mathrm{~K}$ & 28 & $\mathrm{~W}$ & $<1.00$ \\
$\mathrm{Mg}$ & 23 & $\mathrm{As}$ & $<0.50$ \\
$\mathrm{Al}$ & $<5$ & $\mathrm{La}$ & $<0.50$ \\
$\mathrm{Fe}$ & $<5$ & $\mathrm{Li}$ & $<0.50$ \\
$\mathrm{Ti}$ & $<5$ & $\mathrm{P}$ & $<0.50$ \\
$\mathrm{Sr}$ & 1.7 & $\mathrm{Sb}$ & $<0.50$ \\
$\mathrm{Ga}$ & $<1.00$ & $\mathrm{Sc}$ & $<0.50$ \\
$\mathrm{Nb}$ & $<1.00$ & $\mathrm{Te}$ & $<0.50$ \\
$\mathrm{Sn}$ & $<1.00$ & $\mathrm{Ag}$ & $<0.25$ \\
- & - & $\mathrm{Bi}$ & $<0.25$ \\
\hline
\end{tabular}


It is observed in Table 2 that the highest concentration corresponds to sulfur ions. These can react with sodium hydroxide or some component of the tailings causing impurities or unwanted components that alter the results.

The granulometry of the tailings obtained in the laboratory by means of the Ro-Tap test and laser technology is shown in Figure 3.

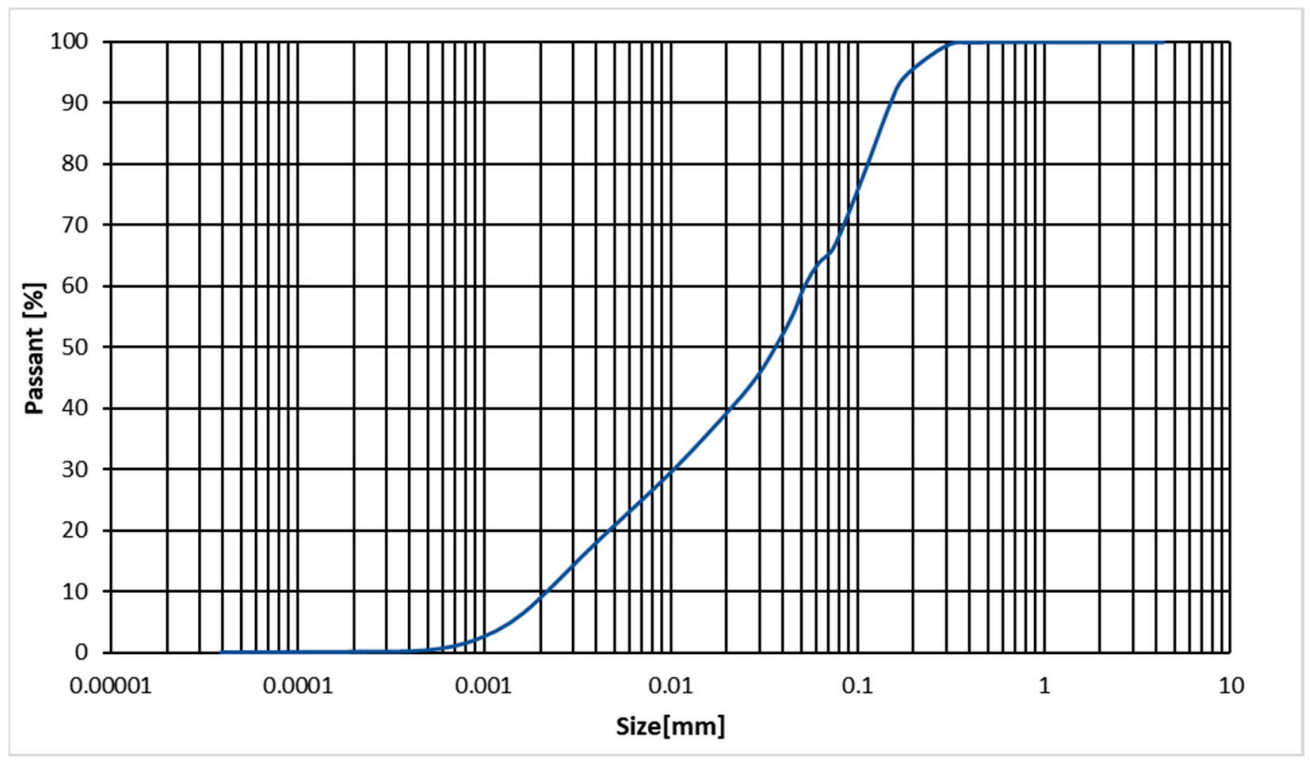

Figure 3. Tailings granulometric curve.

Based on Unified Soil Classification System (USCS) classification tests of tailings and their Atterberg limits, the tailings are classified as a low plasticity silt type soil (ML) according to Figure 4, which is an inorganic silt with low compressibility.

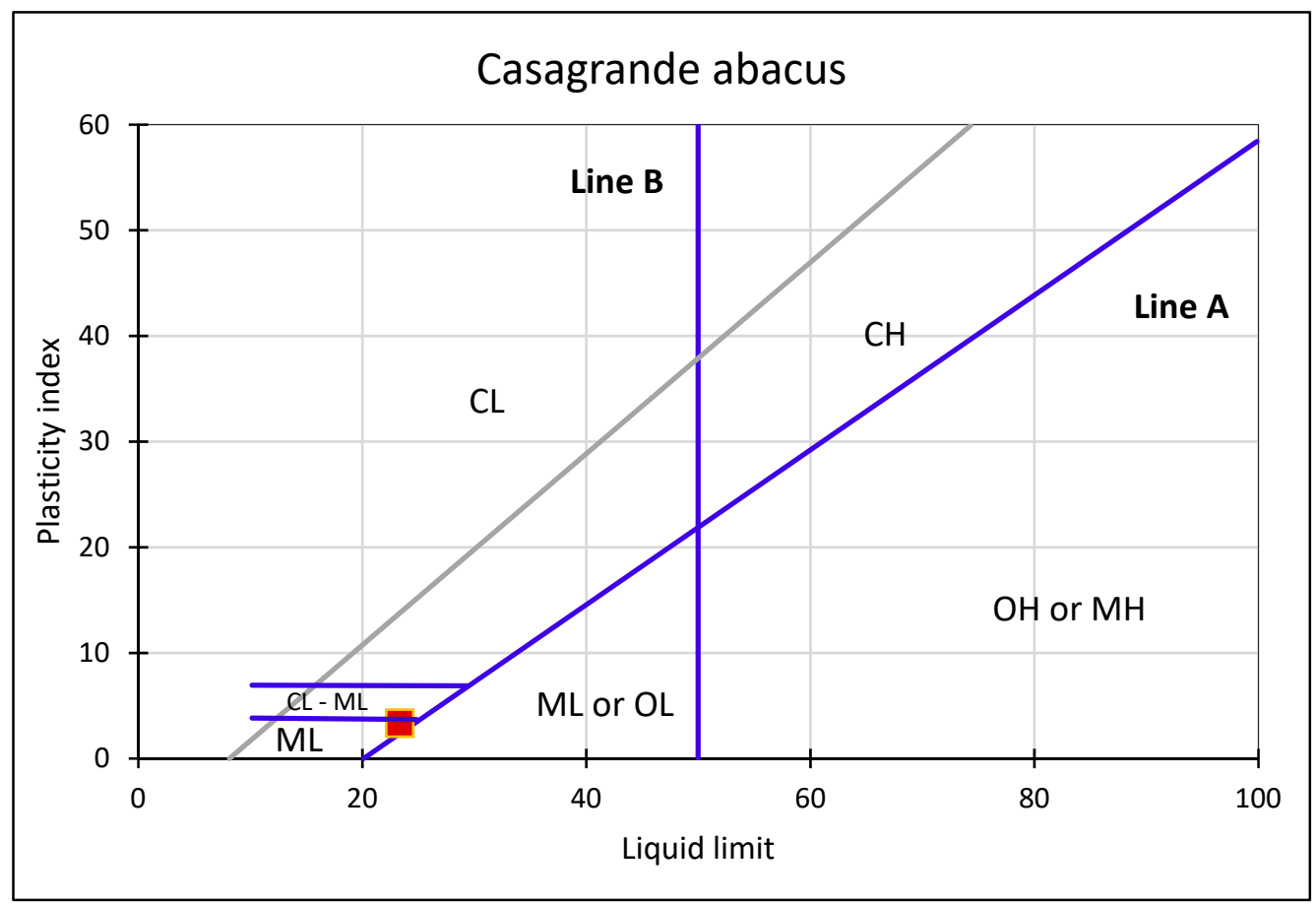

Figure 4. Tailings plasticity chart. 
The Atterberg limits, that is, the water contents in which the behavior of the soil is modified, of the tailings are included in the Table 3.

Table 3. The Atterberg limits of the tailings used.

\begin{tabular}{cc}
\hline Parameter & Value \\
\hline Liquid limit & $23.3 \%$ \\
Plastic limit & $19.7 \%$ \\
Shrinkage limit & $20.5 \%$ \\
Plasticity index & $3.5 \%$ \\
\hline
\end{tabular}

Sodium hydroxide (in pellet form) was purchased from Winkler Ltd.a., Chile, having a purity of $99 \%$. For the dissolution of $\mathrm{NaOH}$, different methods were used, including the previous dissolution of this reagent in process water to create an activating solution of different concentrations depending on the method to be used and the addition of $\mathrm{NaOH}$ directly to the tailing, where it is dissolved in the water included in the tailing.

The steel molds used for the experimentation were $12.5 \mathrm{~cm}$ in height and $6 \mathrm{~cm}$ in diameter. These are the interior measures of the cylindrical mold having a height of $10 \mathrm{~cm}$ and a diameter of $5 \mathrm{~cm}$, which are in order with the standards, where it is recommended, for cylindrical molds, to use a diameter " $\mathrm{d}$ " and a height " $2 \mathrm{~d}$ ". The molds were also greased on their base plate and on the inner cylinder, and finally, a plastic film was put on their base. It is important to check for any leaks on the molds; Figure 5.

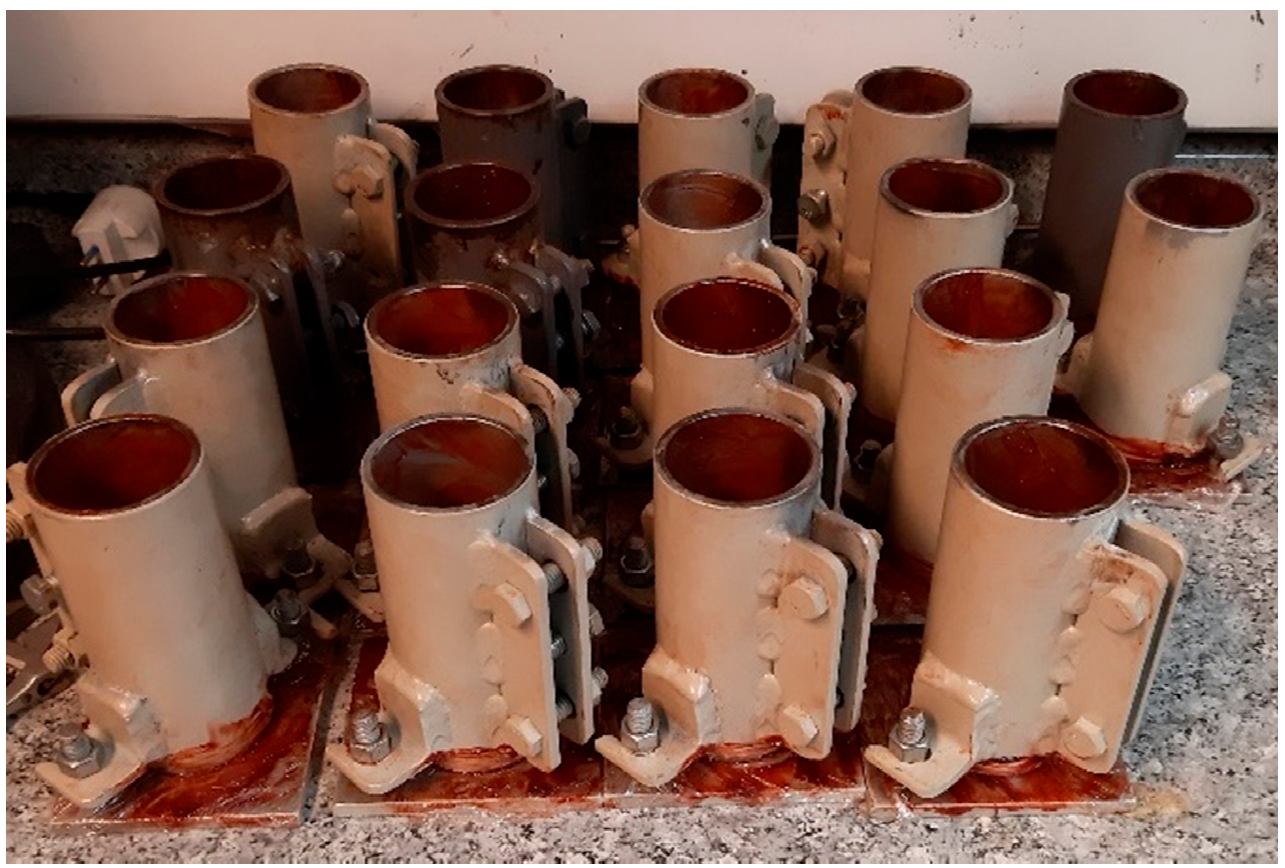

Figure 5. Prepared steel molds.

\subsection{Mix Variables}

For the realization of geopolymer mixtures, the quantities of raw material must be chosen; therefore, the researchers focused mainly on the following variables.

\subsubsection{Alkaline Concentration}

Corresponds to the molar concentration (M) of the alkaline solution used, which may correspond to a sodium hydroxide solution. Multiple previous studies [9,27-29] show that the higher the $\mathrm{NaOH}$ concentration, the higher the compressive strength obtained, while deteriorating the rheological properties of the mixture. It was decided to evaluate 
three levels of molar concentration: 12,14 , and $16 \mathrm{M}$, in order to cover a range that various authors already have investigated.

\subsubsection{Water/Solids Ratio}

The state of the art of geopolymers shows that the higher the water/solids ratio, the lower the resistance, but in turn the better workability of the geopolymer, and vice versa $[13,30,31]$. Due to the above, it was decided to work with water/solid ratio values of $30 \%, 35 \%$, and $40 \%$, which would correspond to Cp values (concentration of solids with respect to pulp) close to $77 \%, 74 \%$, and $71 \%$, respectively. These chosen water/solids ratio values are similar to those used in most previous studies on geopolymers [30,32-35].

The molar concentrations of the alkaline activator and the water/solids ratios to be used in the different mixtures to be created in this research are presented in Table 4 .

Table 4. Proportions of the mixtures to be made.

\begin{tabular}{cccc}
\hline $\mathbf{N}^{\circ}$ & Concentration $[\mathbf{M}]$ & Water/Solids [\%] & Mixture \\
\hline 1 & 12 & 30 & M1-C1 \\
2 & 14 & 30 & M1-C2 \\
3 & 16 & 30 & M1-C3 \\
4 & 12 & 35 & M1-C4 \\
5 & 14 & 35 & M1-C5 \\
6 & 16 & 35 & M1-C6 \\
7 & 12 & 40 & M1-C7 \\
8 & 14 & 40 & M1-C8 \\
9 & 16 & 40 & M1-C9 \\
\hline
\end{tabular}

\subsection{Methodologies}

The following is a description of the 7 different methods developed in this research for the production of geopolymers based on copper tailings and sodium hydroxide.

\subsubsection{Method I}

This consisted of taking a sample of homogenized tailings pulp with a solids concentration $\mathrm{Cp}=83 \%$, and the remaining water was added to meet the water/solid ratio defined in Table 4 . The corresponding quantity to obtain the molar concentration of $\mathrm{NaOH}$ defined in Table 4 was added. The raw materials were mixed for 15 min with a mechanical stirrer and deposited in the molds shown in Figure 5. The mixes were set for 7 days at room temperature to observe if their consistency was sufficient to be removed from the mold. This method applied to the nine mixtures presented in Table 4. After being set for 7 days at room temperature, they were placed in an oven at a curing temperature of $60{ }^{\circ} \mathrm{C}$ for a period of 7 more days.

\subsubsection{Method II}

This consisted of taking the mixture M1-C3 according to Table 4 and dissolving the $\mathrm{NaOH}$ only in the amount of missing water to complete the $\mathrm{Cp}=83 \%$ in the total mixture. The $\mathrm{NaOH}$ was diluted for $15 \mathrm{~min}$ in water at room temperature with a mechanical stirrer. The mixture was maintained at room temperature while waiting for the temperature to drop. The solution was added to the tailings pulp, and mixed for $15 \mathrm{~min}$ with a mechanical stirrer to later be deposited in the molds shown in Figure 5. Its consistency was observed after $24 \mathrm{~h}$ of setting at room temperature to enable comparison with Method I.

\subsubsection{Method III}

This method took the characteristics of the M1-C3 mixture according to Table 4, and dissolved the $\mathrm{NaOH}$ in the $100 \%$ of water necessary to bring the tailings pulp to a solid concentration $\mathrm{Cp}=83 \%$. Subsequently, this solution was incorporated into the tailings that already had a solids concentration $\mathrm{Cp}=83 \%$. The total mixture $\left(\mathrm{H}_{2} \mathrm{O}+\mathrm{NaOH}+\right.$ tailings 
pulp $\mathrm{Cp}=83 \%$ ) had a water/solids ratio of approximately $50 \%$, which was mixed for 15 min with a mechanical stirrer. Its consistency was observed after $24 \mathrm{~h}$ of setting at room temperature to enable comparison with the other methods.

\subsubsection{Method IV}

This method was similar to Method II, in which the mixture M1-C3 was used according to Table 4 , but, in this case, the $\mathrm{H}_{2} \mathrm{O}+\mathrm{NaOH}$ solution was added to the tailings pulp in less than a minute, making the exothermic reaction occur together with the tailings. Its consistency was observed after $24 \mathrm{~h}$ of setting at room temperature to enable comparison with the other methods.

\subsubsection{Method V}

This method consisted of the same procedure indicated for Method IV, with the difference that, after mixing for $15 \mathrm{~min}$, the mixture was subject to a thermal bath at a controlled temperature of $23{ }^{\circ} \mathrm{C}$ for a setting time of $24 \mathrm{~h}$. Its consistency was observed after $24 \mathrm{~h}$ of setting at room temperature to enable comparison with the other methods.

\subsubsection{Method VI}

For this method, the tailings were dried to work as close as possible to the methodology presented in previous investigations $[3,18,36,37]$. When the tailings were dry, the alkaline solution was prepared with the corresponding amounts of water and $\mathrm{NaOH}$ in order to comply with the parameters of the M1-C3 mixture. The mixture of $\mathrm{H}_{2} \mathrm{O}+\mathrm{NaOH}+$ dry tailings was mixed for 15 min with a mechanical stirrer and then placed in the molds (Figure 5). Its consistency after $24 \mathrm{~h}$ of setting at room temperature was observed to enable comparison with the other methods. Simultaneously, this method was replicated using a water/solids ratio of $20 \%$ for a curing process at $60{ }^{\circ} \mathrm{C}$ for $24 \mathrm{~h}$ and another for 7 days. Additionally, a duplicate was cured in an oven at a temperature of $90{ }^{\circ} \mathrm{C}$ for $24 \mathrm{~h}$ and another for 7 days. Due to the composition of the tailings used and its low reactivity when in contact with the alkaline solution, it is necessary to cure the mixtures with the application of external heat, i.e., they must be cured in an oven. The choice of temperatures and curing times were based on studies previously carried out in the creation of geopolymers based on copper tailings.

\subsubsection{Method VII}

The objective of this method was to use the water contained in the tailings without the addition of extra liquid. Therefore, we worked with the wet tailings ( $\mathrm{Cp}=83 \%$ ) and based on the water already in the tailings, the amount of $\mathrm{NaOH}$ was added until a $\mathrm{NaOH}$ molar concentration of $19 \mathrm{M}$ was reached. From this mixture, a water/solids ratio $=20.5 \%$ was obtained. After the addition of $\mathrm{NaOH}$, the geopolymeric mixture was stirred manually with a paddle until it had the necessary consistency to be stirred mechanically. The total stirring time was $30 \mathrm{~min}$, alternating between manual and mechanical stirring. After stirring, the mixture was placed in metal molds (Figure 5) and placed in the oven to cure at $60^{\circ} \mathrm{C}$ for 1 and 7 days, and at $90^{\circ} \mathrm{C}$ for a period of 7 days.

This method is more relevant than the previous ones because one of the objectives of this study is to generate a geopolymer made from copper tailings to be used as the filling of stopes in underground mining. As a result, it would be favorable to use the filtered tailings without the need to dry it prior to use.

\subsection{Testing Procedure}

To analyze the alkalinity of the system, $\mathrm{pH}$ measurements were performed on the fresh geopolymer pastes using a DFRobot digital $\mathrm{pH}$ meter previously calibrated between $\mathrm{pH} 7$ and 13 , at a controlled temperature of $20^{\circ} \mathrm{C}$. 
At the same time as the $\mathrm{pH}$ measurements were made, temperature measurements were taken on the fresh geopolymer pastes, using a digital thermometer, in order to obtain the temperature of the mixtures at all times during agitation.

Rheological measurements of some geopolymer pastes were carried out using a HAAKE RheoStress 6000 rheometer with a FL100 paddle probe at different times after stirring ( 0 to $4 \mathrm{~h}$ post-stirring), using a shear rate of $0.11 / \mathrm{s}$ for $60 \mathrm{~s}$.

Finally, a visual analysis of the geopolymers was carried out, based on their consistency after curing.

\section{Results}

\subsection{Method I}

Figure 6 shows the sample made with Method I, which presented a low consistency. After $24 \mathrm{~h}$ of setting at room temperature, the mixtures failed to harden. It was observed that on its face exposed to the air, the mixture formed a layer of a whitish product, which is attributed to carbonation produced by excess $\mathrm{NaOH}$ in contact with the $\mathrm{CO}_{2}$ present in the air, and indicates a possible decrease in alkalinity during the process, as indicated by several authors [38-40], thus damaging the mechanical properties of the geopolymer.

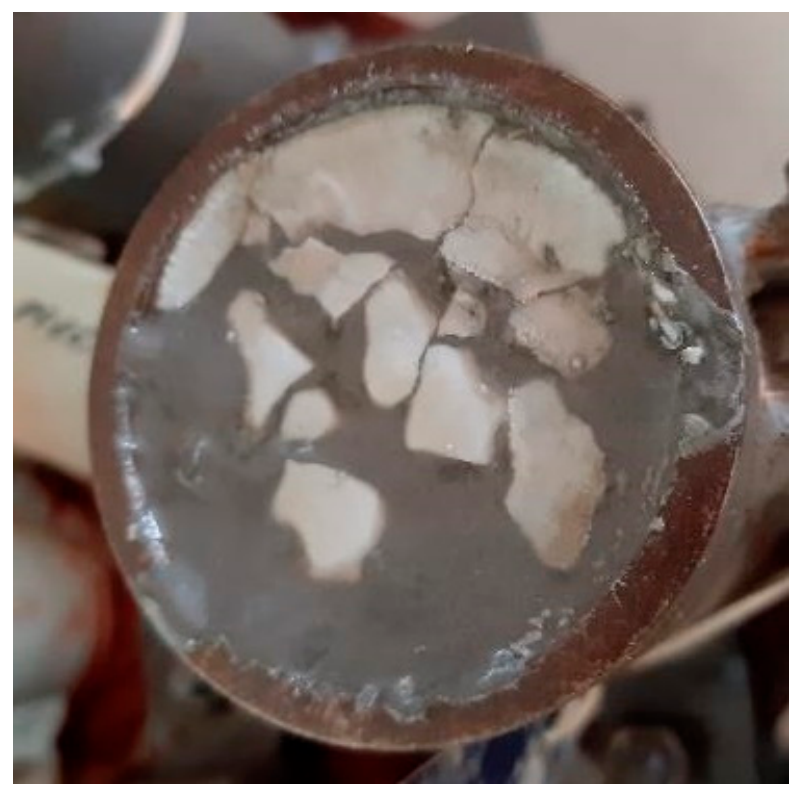

Figure 6. Carbonation observed in the geopolymer created by Method 1 with $24 \mathrm{~h}$ at room temperature.

According to the phase diagram of the $\mathrm{NaOH}-\mathrm{H}_{2} \mathrm{O}$ system presented in the study of Provis [41], it is observed that $\mathrm{NaOH}$ has a dissolution of more than $70-80 \%$ in water, at a temperature between 70 and $80^{\circ} \mathrm{C}$. Hence, due to the temperature of the pulp, adding the $\mathrm{NaOH}$ directly to the tailings pulp does not ensure the defined concentration is obtained.

The mixtures made for this method according to Table 4, after 7 days set at room temperature, were entered into an oven at a curing temperature of $60{ }^{\circ} \mathrm{C}$ for 7 days to observe their behavior, which did not vary, resulting in greater carbonation and no hardening, as shown in Figure 7. 


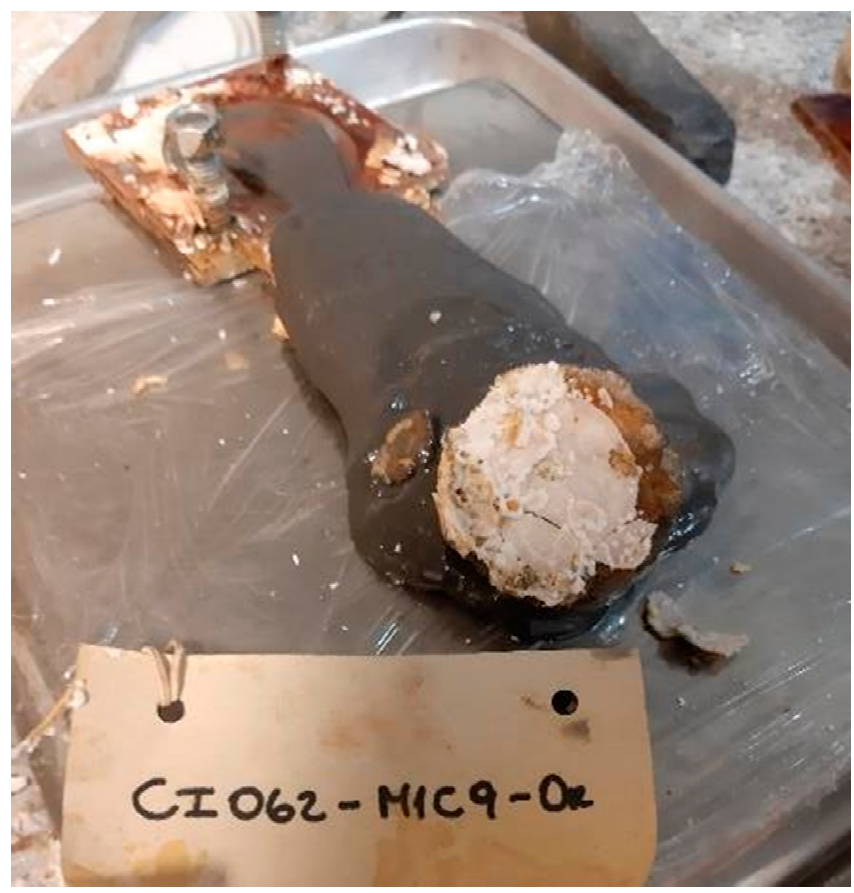

Figure 7. Carbonation observed in the geopolymer created by Method 1, cured for 7 days at $60{ }^{\circ} \mathrm{C}$.

\subsection{Method II}

Figure 8 shows the consistency of the mixture made with Method II, where a better consistency was observed compared to Method I; however, the mixture did not present hardening after $24 \mathrm{~h}$ of setting at room temperature.

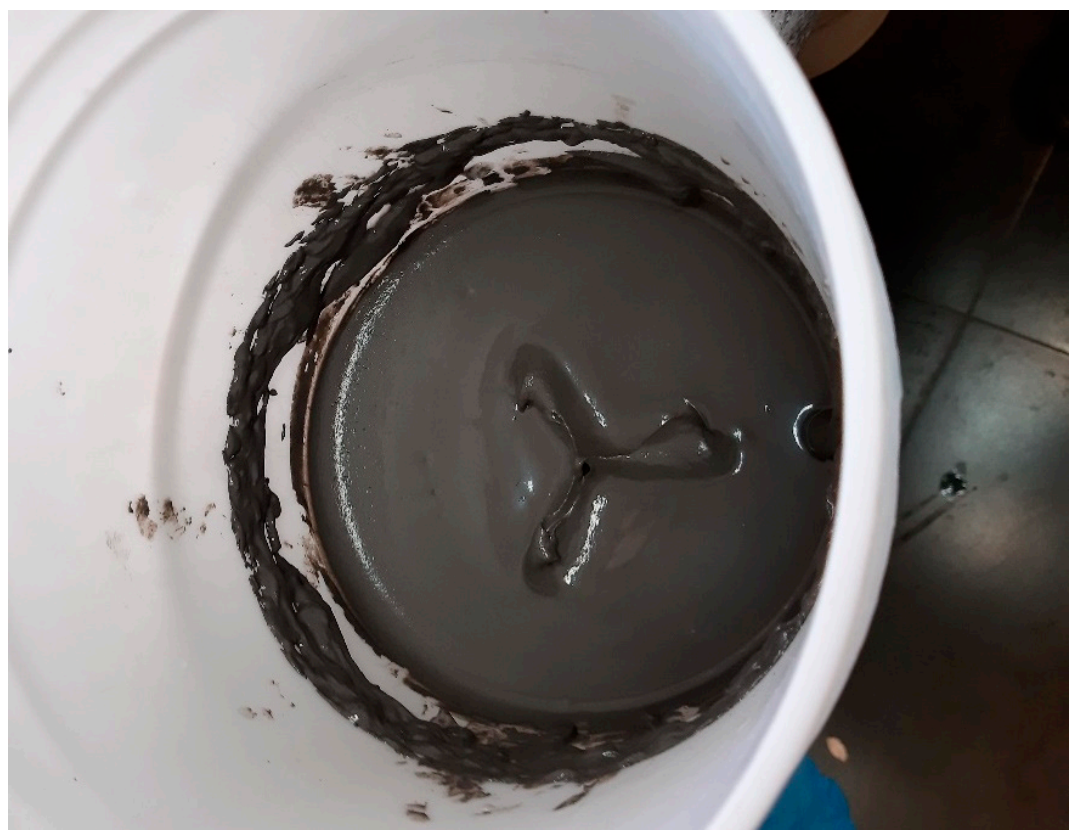

Figure 8. Consistency of Method II, 1 day set at room temperature.

The loss of solubility of $\mathrm{NaOH}$ at low temperatures, as mentioned in Method $\mathrm{I}$, is only about $45 \%$ at a temperature of $23{ }^{\circ} \mathrm{C}$, and crystallization was observed in the $\mathrm{NaOH}$ dissolution, as seen in Figure 9. 


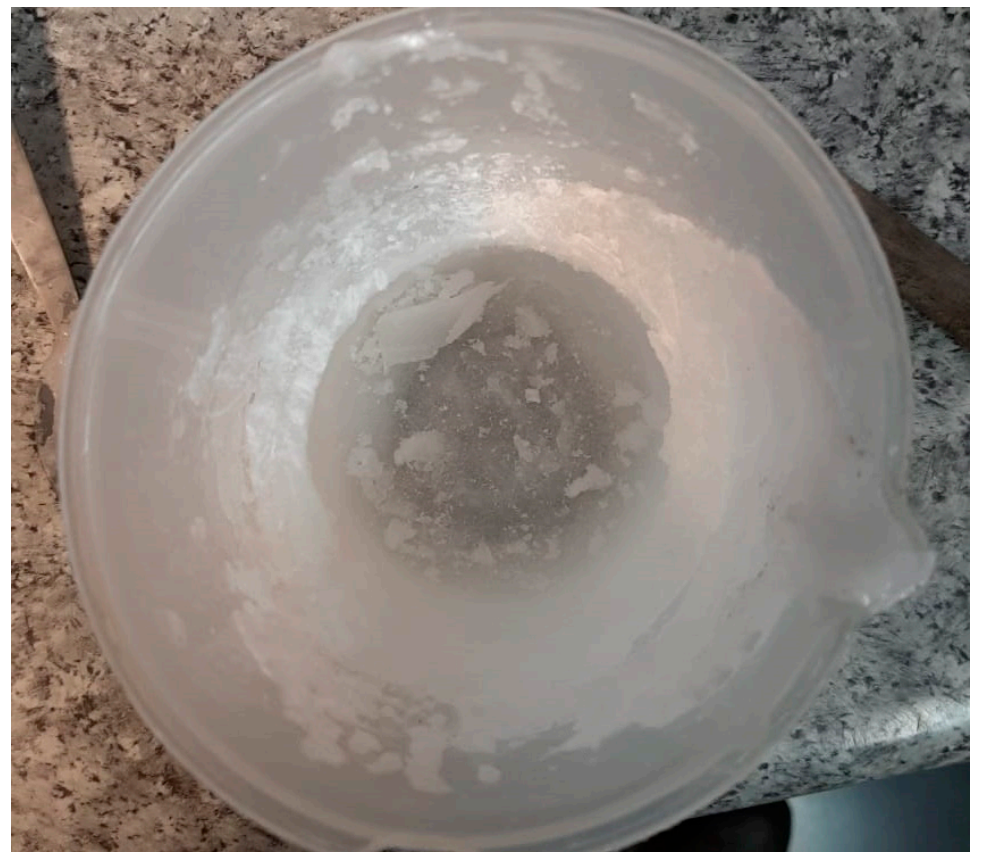

Figure 9. Crystallized sodium hydroxide from the alkaline solution of Method II.

\subsection{Method III}

Figure 10 shows a mixture made with Method III, where the ratio of water/solids was increased and the concentration of $\mathrm{NaOH}$ was simultaneously decreased. Dissolving the $\mathrm{NaOH}$ in a greater amount of water allowed for better workability and dissolution; however, given the temperature of the water, it was estimated that the solubility of $\mathrm{NaOH}$ was low.

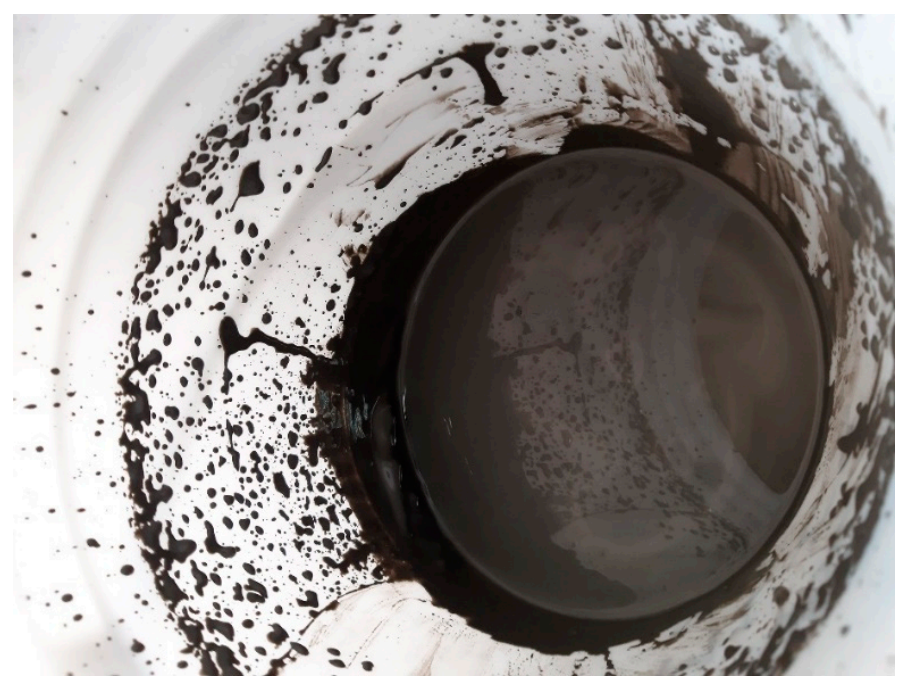

Figure 10. Consistency of Method III, 1 day set at room temperature.

This mixture presented a very low consistency and obtained a completely liquid produce; thus, after $24 \mathrm{~h}$ of setting at room temperature, no hardening was obtained.

The effect of increasing the water/solids ratio and decreasing the $\mathrm{NaOH}$ concentration, in which adding the water content to the tailings pulp was not considered, generated a mixture with a liquid and non-moldable consistency. 


\subsection{Method IV}

The consistencies obtained with this method were better than those of the previous methods, according to the observation in Figure 11; however, after $24 \mathrm{~h}$ of setting at room temperature, this mixture failed to harden. It was observed that during the stirring process, this mixture showed a greater consistency than that of the previous methods, and achieved greater stability.

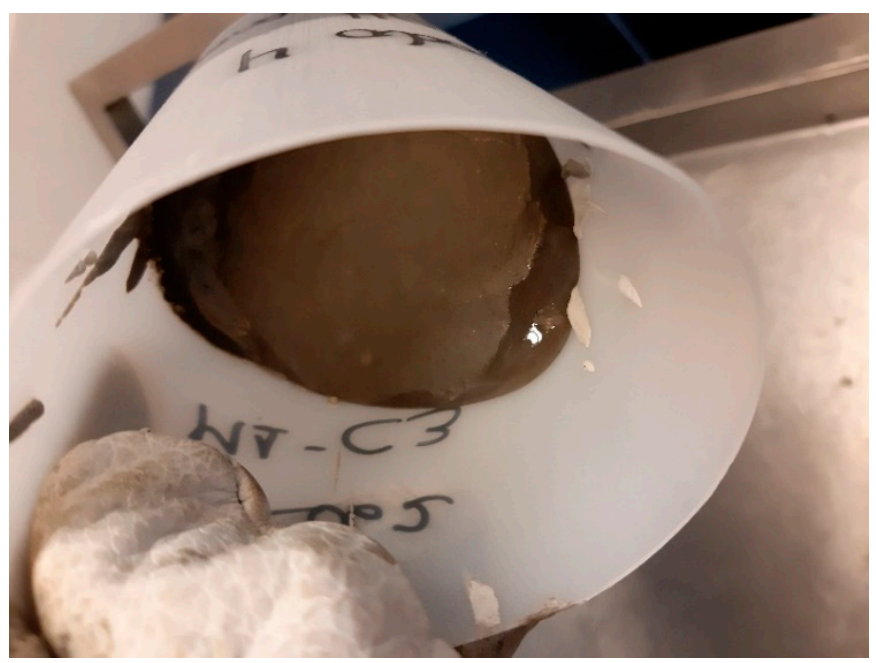

Figure 11. Consistency of Method IV, 1 day set at room temperature.

The immediate addition of the supersaturated $\mathrm{NaOH}$ solution to the tailings was beneficial for the mixture because it was possible to work with the necessary amount of alkali. In addition, the kinetics of $\mathrm{NaOH}$ [42] and its exothermic reaction were fully exploited.

\subsection{Method V}

Figure 12 shows the consistency of a mixture made with Method V, where it was observed that its consistency was more liquid compared to the previous method. The condition of introducing the mold to a thermal bath did not favor the consistency of the sample; on the contrary, it was harmed by becoming more liquid and losing shape.

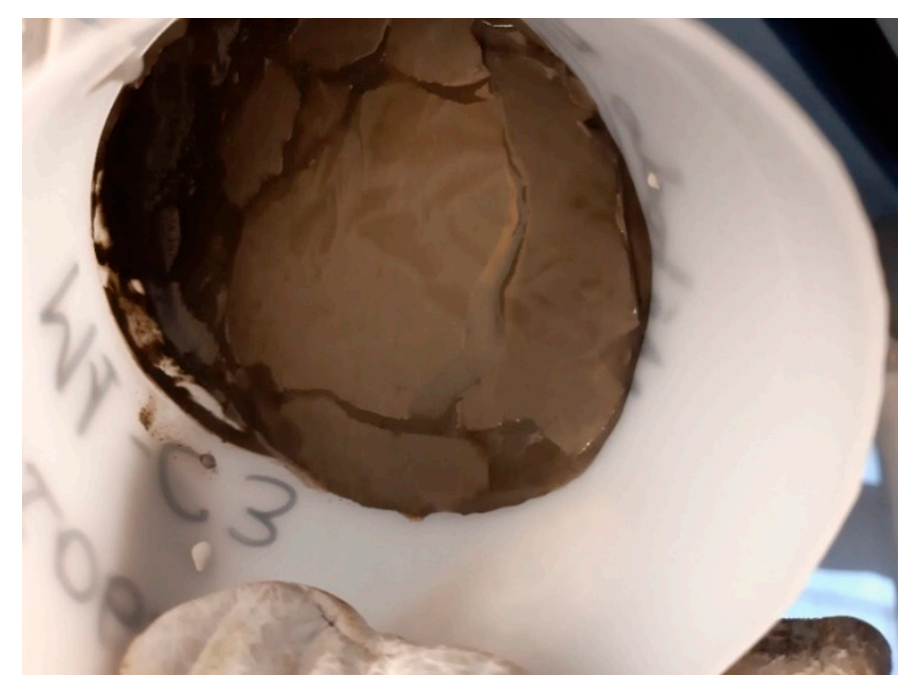

Figure 12. Consistency of Method V, 1 day of thermal bath at $23^{\circ} \mathrm{C}$. 


\subsection{Method VI}

Figure 13 shows the consistency of a mixture made with Method VI, where a better consistency was observed. With $24 \mathrm{~h}$ of setting at room temperature, it was observed that it did not achieve hardening.

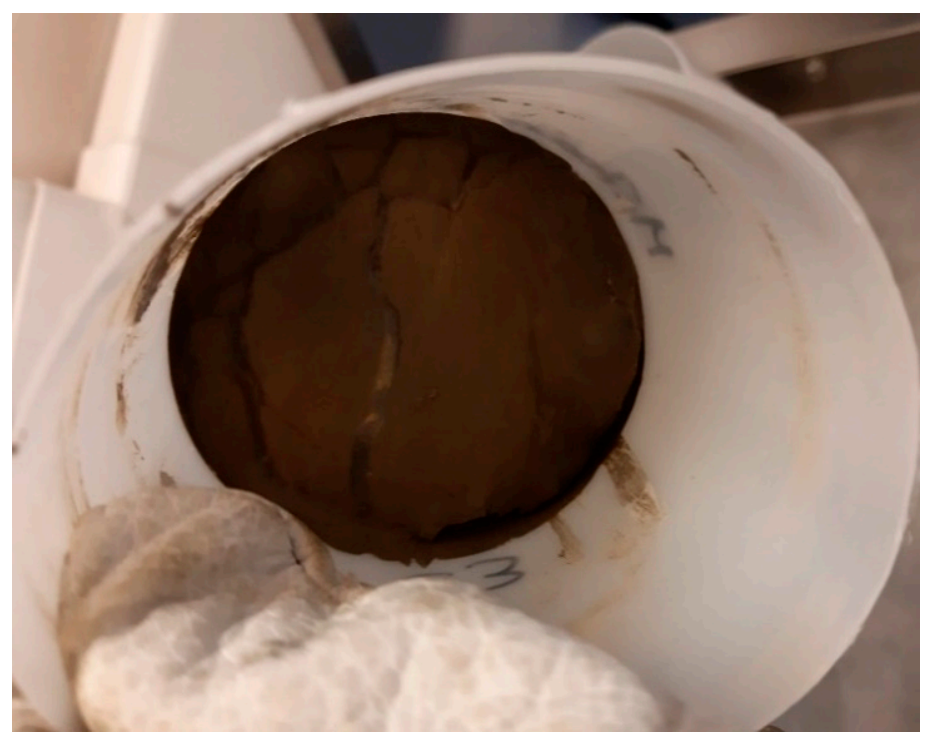

Figure 13. Consistency of Method VI, 1 day set at room temperature.

For the same mixture but cured at $60^{\circ} \mathrm{C}$ for 1 and 7 days, consistencies similar to a clay-silty were obtained (Figures 14 and 15).

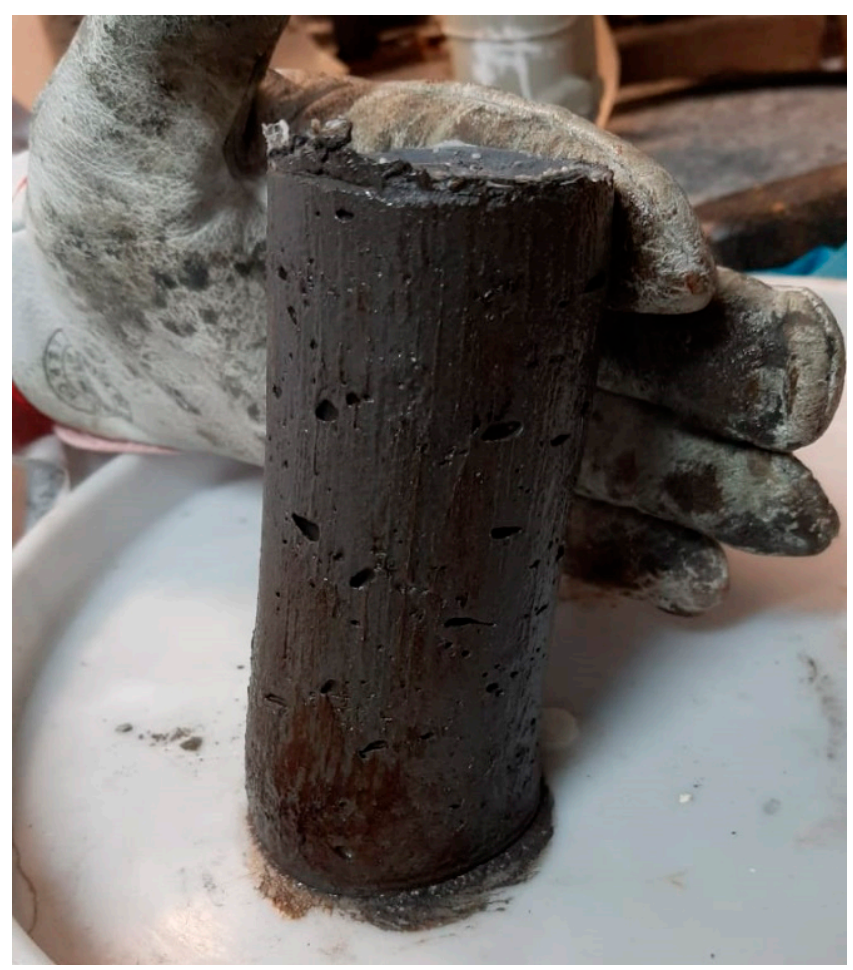

Figure 14. Consistency of Method VI with water/solids ratio of $20 \%, 1$ day at $60^{\circ} \mathrm{C}$. 


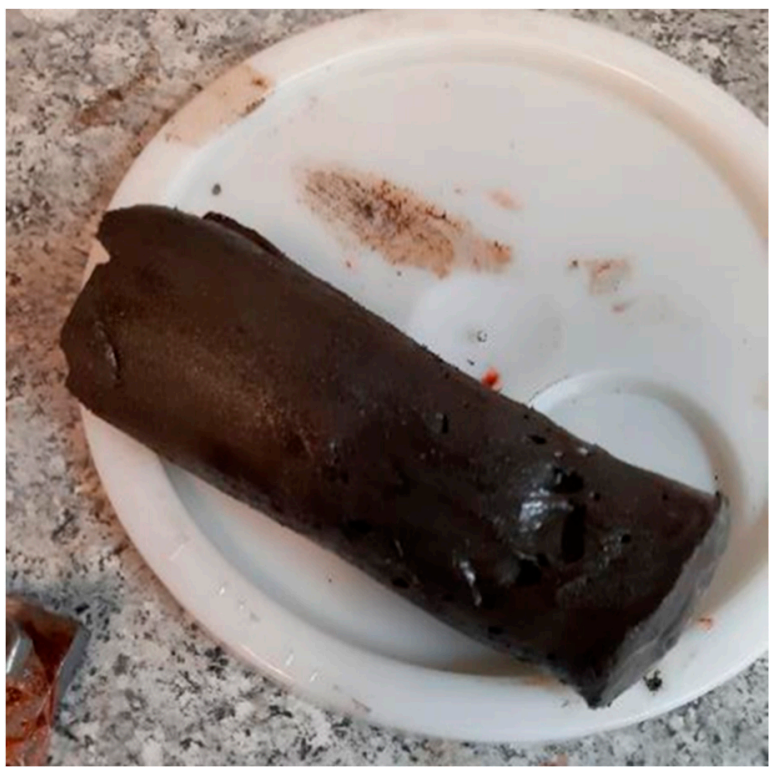

Figure 15. Consistency of Method VI with water/solids ratio of $20 \%, 7$ days at $60{ }^{\circ} \mathrm{C}$.

For the mixture cured at $90{ }^{\circ} \mathrm{C}$ for 1 and 7 days, consistencies with higher hardening were obtained, and it managed to maintain its shape with a remarkable hardness (Figure 16). This result demonstrates that the curing temperature plays an important role in the generation of the N-A-S-H gel, as indicated by previous authors [2,8,22,43]. Moreover, this result is similar to those obtained previously by several authors $[2,3,5,22,25,43-45]$, who worked by separately varying the curing temperature of geopolymers based on fly ash and mine tailings. In most cases, the optimum curing temperature was in the range between 80 and $90{ }^{\circ} \mathrm{C}$ because at these temperatures the highest compressive strengths were obtained (see Figure 17).

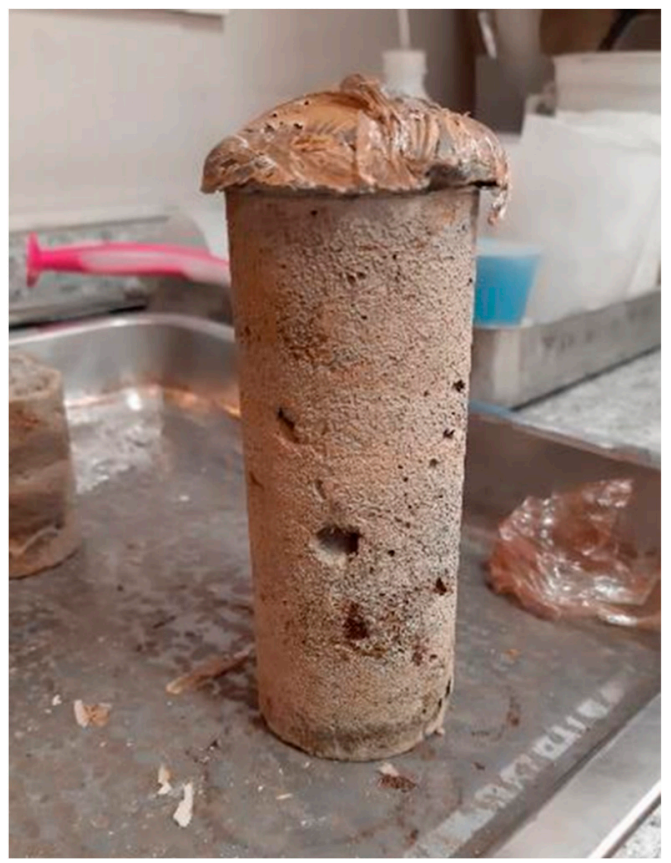

Figure 16. Consistency of Method VI with water/solids ratio of $20 \%, 7$ days at $90{ }^{\circ} \mathrm{C}$. 


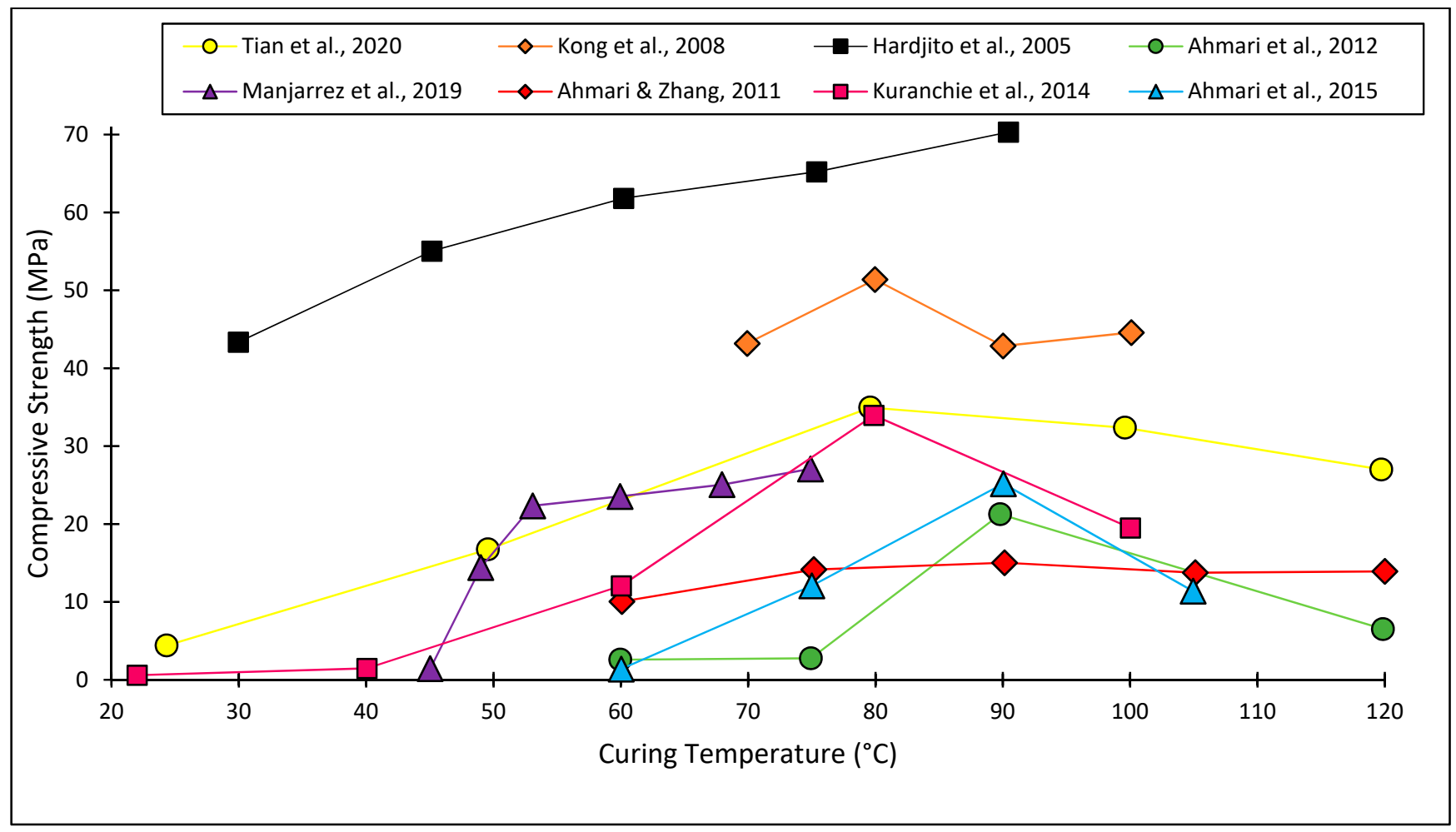

Figure 17. Compressive strength as a function of curing temperature; data obtained from previous investigations [2,3,5,22,25,43-45].

\subsection{Method VII}

The operation and preparation of these mixtures in the laboratory was difficult because the sodium hydroxide added in its pure state to the tailings pulp made it more consistent and thicker, thus making it difficult to mix with the mechanical stirrer. Therefore, stirring was performed manually for $15 \mathrm{~min}$ to integrate the $\mathrm{NaOH}$ into the tailings pulp, to enable subsequent working with the mechanical agitator for an additional $15 \mathrm{~min}$.

The mixtures that were cured for 1 day at a temperature of $60^{\circ} \mathrm{C}$ showed a consistency similar to a clay soil or a consistent mud; however, as time passed, the samples lost their shape, as shown in Figure 18.

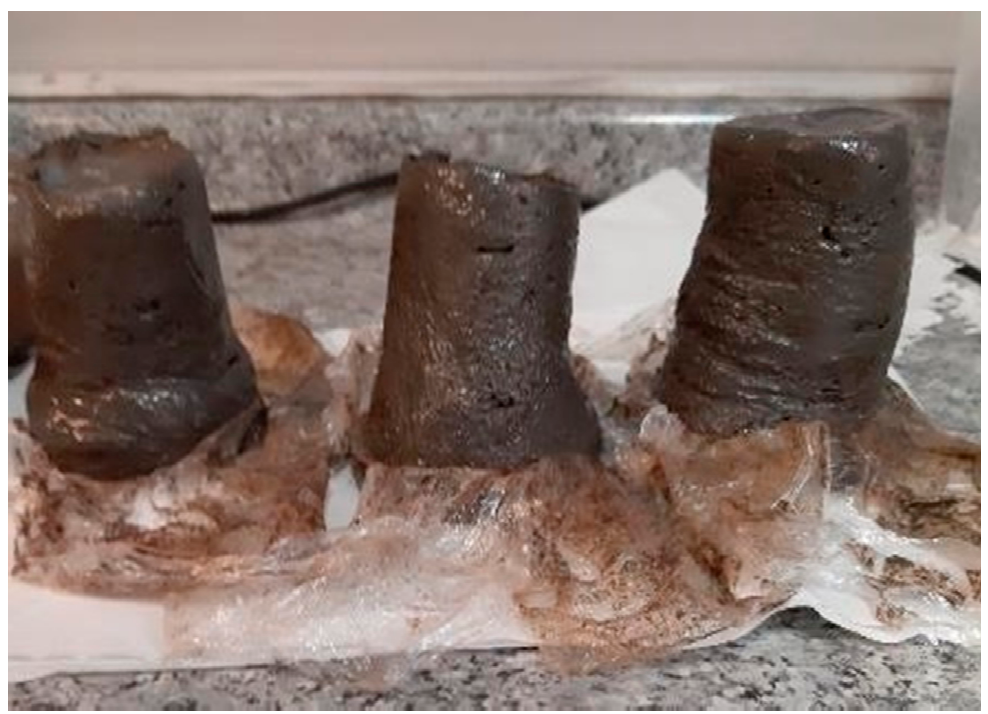

Figure 18. Consistency of Method VII, cured at $60^{\circ} \mathrm{C}$ for $24 \mathrm{~h}$. 
The mixtures that remained for 7 days at a curing temperature of $60{ }^{\circ} \mathrm{C}$ (Figure 19) achieved a better consistency, compared to the mixture cured for $24 \mathrm{~h}$ at $60^{\circ} \mathrm{C}$ (Figure 18). It follows that the formation of N-A-S-H gel is a slow process, and that the main variables to be controlled in order to obtain hardened geopolymers are temperature and curing time.

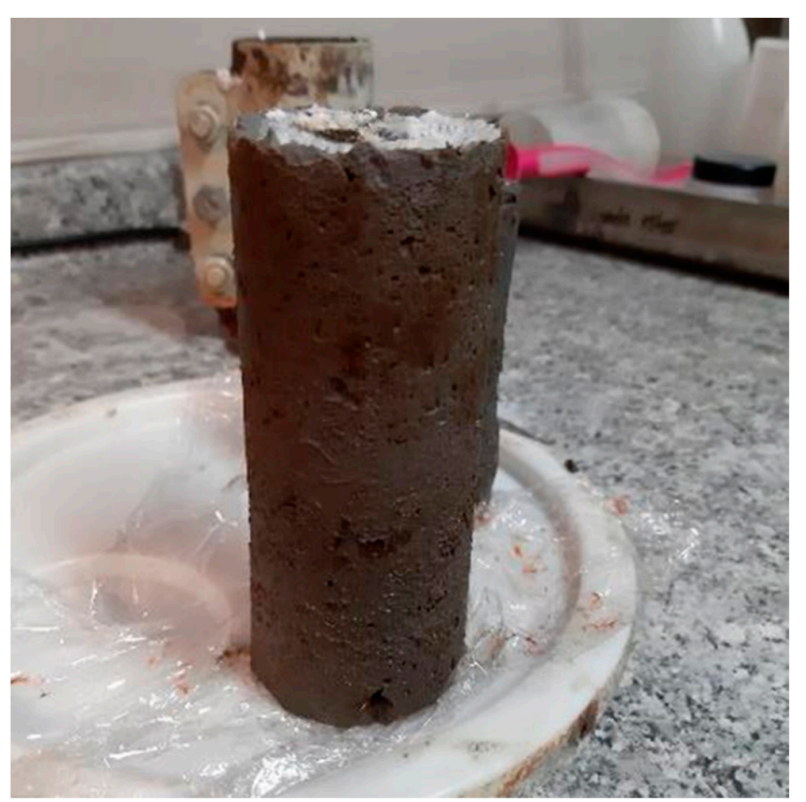

Figure 19. Consistency of Method VII, 7 days at $60^{\circ} \mathrm{C}$.

The mixtures that remained for 7 days at a curing temperature of $90{ }^{\circ} \mathrm{C}$ managed to maintain their shape with remarkable hardness, similar to a concrete grout specimen (Figure 20). This confirms that increasing the curing temperature from 60 to $90{ }^{\circ} \mathrm{C}$ produces a significant increase in the hardening of copper tailings-based geopolymers, as shown in Figures 15, 16, 19 and 20.

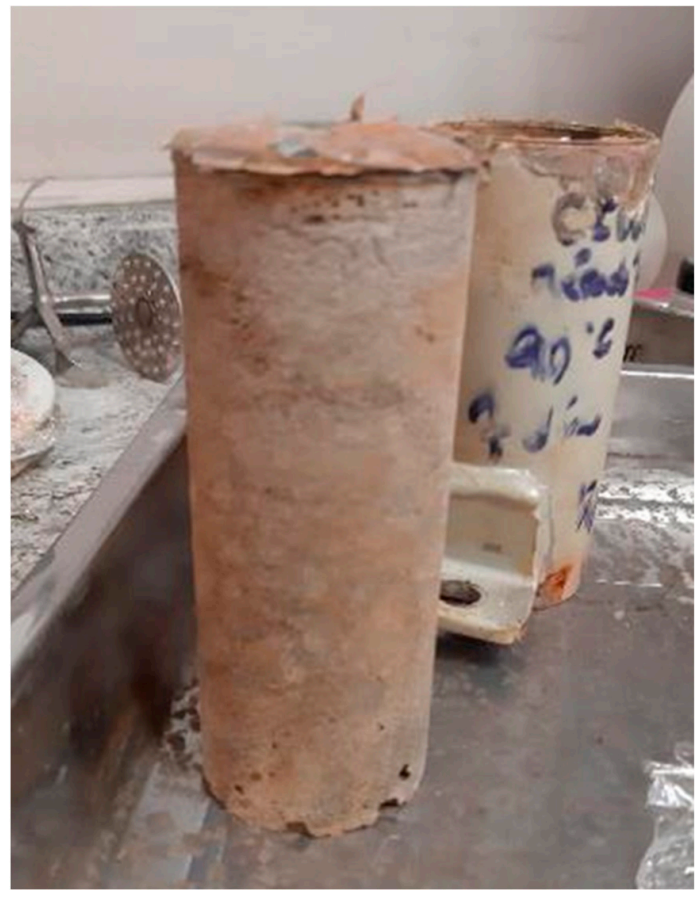

Figure 20. Consistency of Method VII, 7 days at $90^{\circ} \mathrm{C}$. 
Figure 21 shows the interior of a specimen created using Method VII cured at $90{ }^{\circ} \mathrm{C}$ for 7 days, following a petrographic study. From this study it was found that the sample corresponds to a pyroclastic rock of vesicular texture, which is mainly composed of plagioclase and quartz, and to a lesser extent calcite. It presents a level of holohyaline crystallinity; that is, the sample is of a high crystallinity, composed of $95 \%$ vitroclasts. Furthermore, in the size classification, the sample is classified as an ash $(<2 \mathrm{~mm})$.

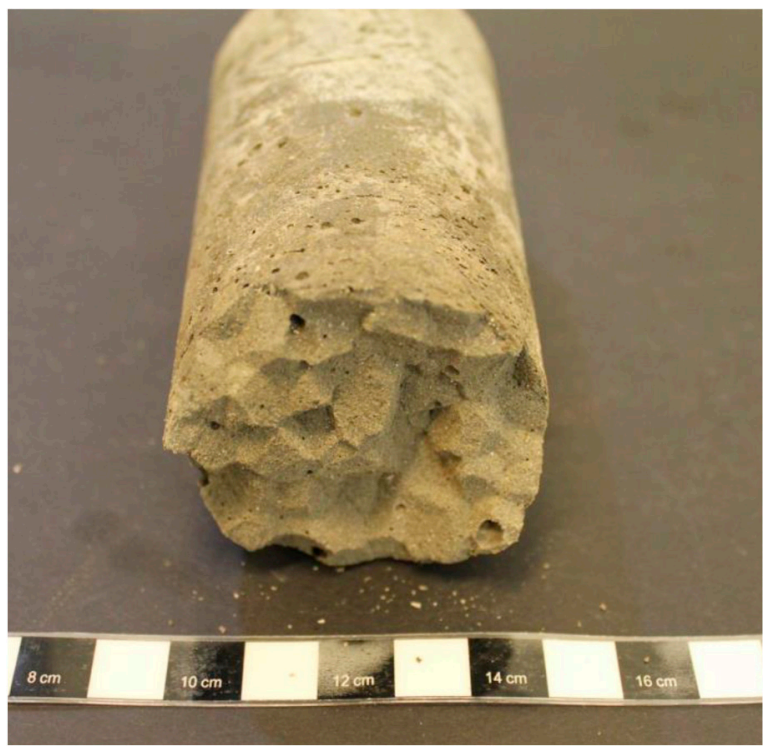

Figure 21. Sample created using Method VII after petrographic study.

Due to the good consistency of the mixture and subsequent hardness of the geopolymer cured using this method, in addition to being the most feasible mixture for the industrial production of geopolymers, the geopolymeric mixture was repeated, but this time, measurements of both $\mathrm{pH}$ and temperature were taken at all times during mixing. The results of these measurements are shown in Figures 22 and 23.

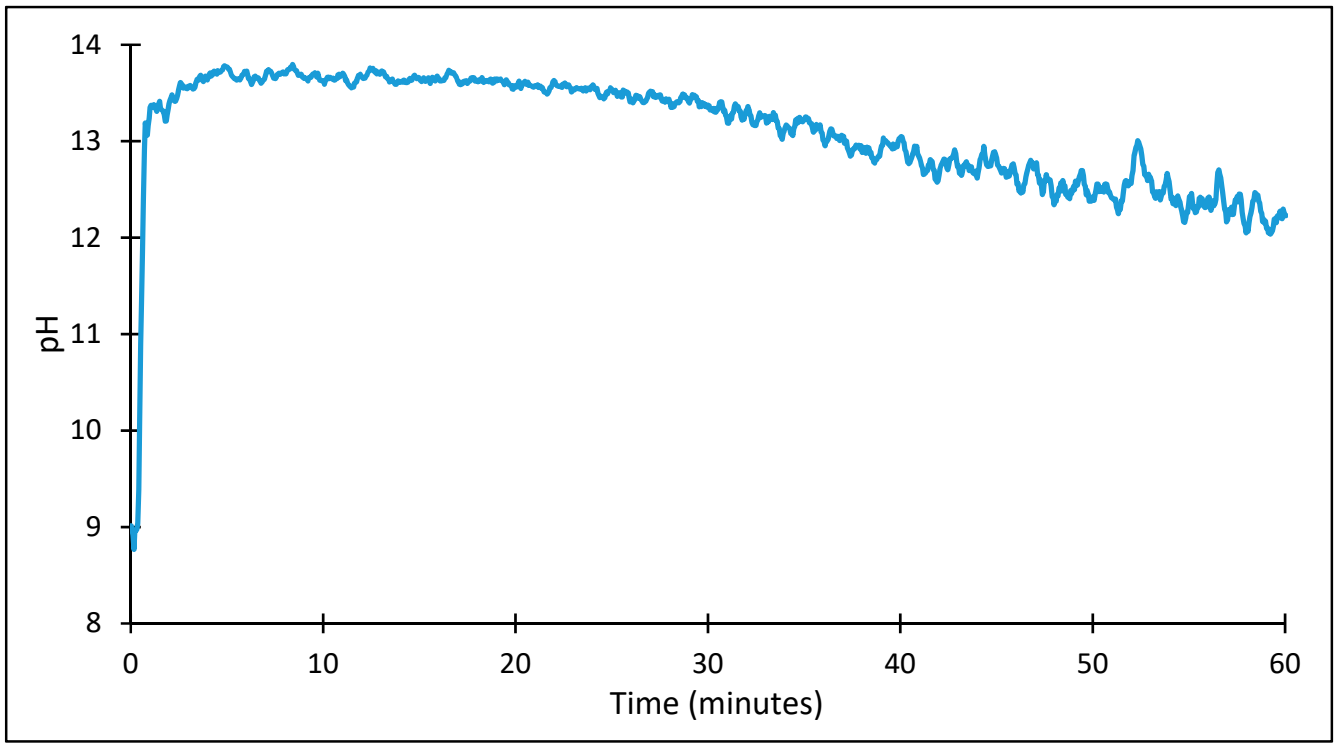

Figure 22. $\mathrm{pH}$ values of fresh geopolymer paste using Method VII. 


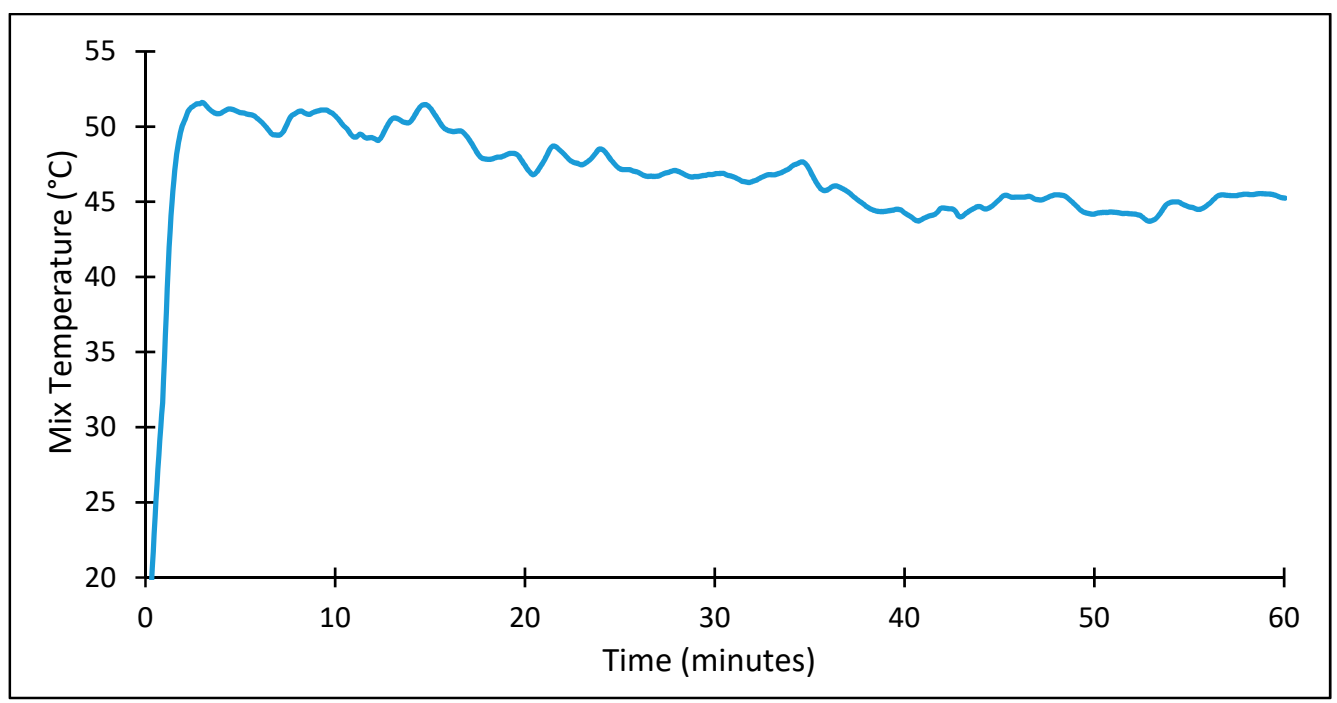

Figure 23. Temperature of fresh geopolymer paste using Method VII.

From the $\mathrm{pH}$ measurements obtained (Figure 22) it can be observed that the mixture increases its $\mathrm{pH}$ rapidly to a value of 13.8 due to the dissolution of the $\mathrm{NaOH}$ in contact with the water coming from the tailings. This indicates that the alkalinity of the system is in the correct range, because most authors recommend working in a $\mathrm{pH}$ range between 13 and 14 [46-49], in order to obtain a good dissolution of the aluminosilicates coming from the source, which later contribute to the formation of the NASH gel. In addition, it can be observed that the $\mathrm{pH}$ of the mixture remained relatively constant during the first $20 \mathrm{~min}$ of the test, after which the $\mathrm{pH}$ began to decay, and reached a $\mathrm{pH}$ value close to 12 after $1 \mathrm{~h}$ of the test. This may be associated with the fact that the hydroxide ions decrease in concentration as they generate complexes with the other elements present in the mixture (such as silicon and aluminum) to subsequently generate the geopolymer. Figure 23 shows that the temperature of the geopolymeric mixture rose rapidly in the first minutes of the test. This is due to the dissolution of $\mathrm{NaOH}$ in the water coming from the tailing, where this dissolution, being an exothermic reaction, generates heat. The maximum temperature reached by the mixture was $51.6^{\circ} \mathrm{C}$. At this temperature, the solubility of $\mathrm{NaOH}$ in water is approximately $60 \%$, which means that not all of the $\mathrm{NaOH}$ added to the mixture was dissolved, and an undissolved amount remained.

After the $\mathrm{pH}$ and temperature tests, rheology tests were carried out on the mixture at different times after agitation, in which five measurements were made with $1 \mathrm{~h}$ difference between them (Figure 24). From these results it is observed that the longer the time after mixing, the higher the yield strength of the fresh geopolymer paste, which increased from $1140 \mathrm{~Pa}$ at time 0 to $1370 \mathrm{~Pa}$ at $4 \mathrm{~h}$ after mixing.

From the results of the compressive strength test performed on the geopolymer created using Method VII, cured for 7 days at $90{ }^{\circ} \mathrm{C}$ (Figure 25), a maximum compressive strength of $19 \mathrm{MPa}$ was obtained, which is a high value of compressive strength and is similar to those obtained in previous studies of geopolymers based on copper tailings. Therefore, this geopolymer could be used for industrial applications that demand materials with good compressive strength. However, this maximum compressive strength was obtained with a $2 \%$ deformation, which is a high value compared to the typical deformation of concrete. 


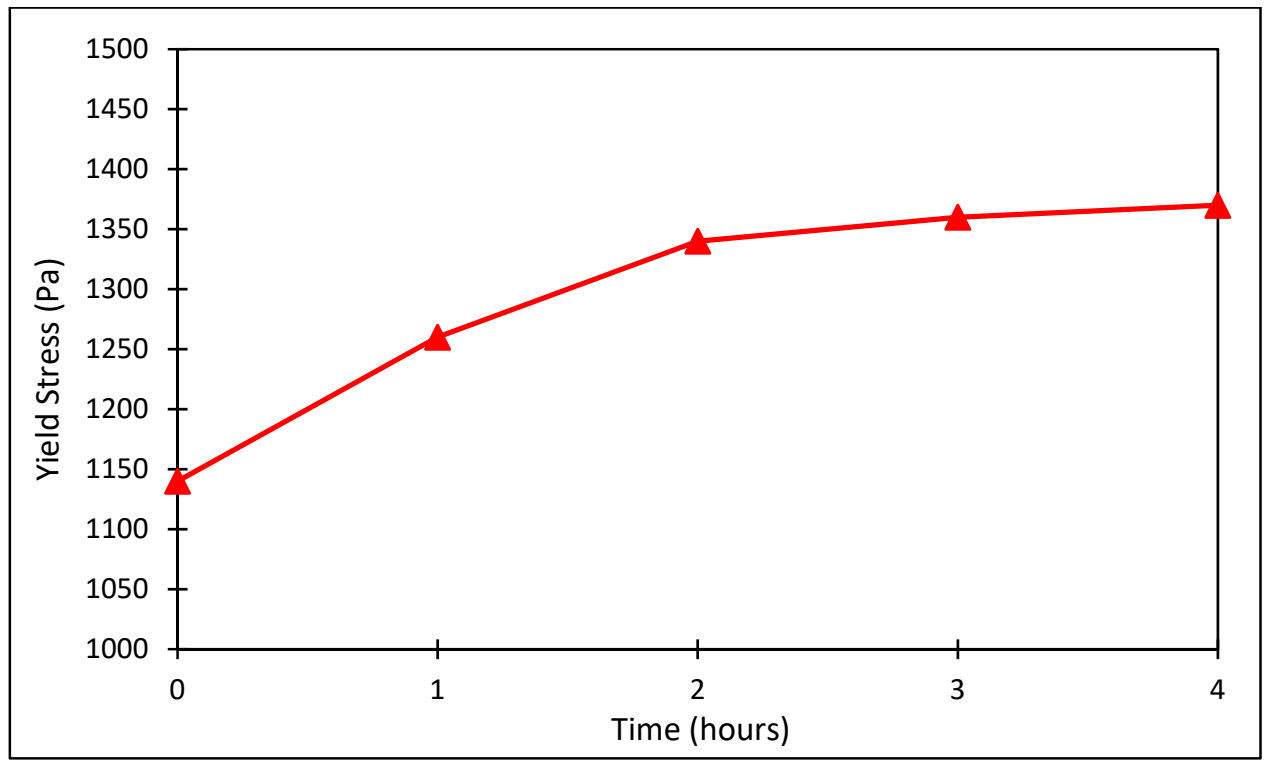

Figure 24. Rheology curves of mixture VII at different times after mixing.

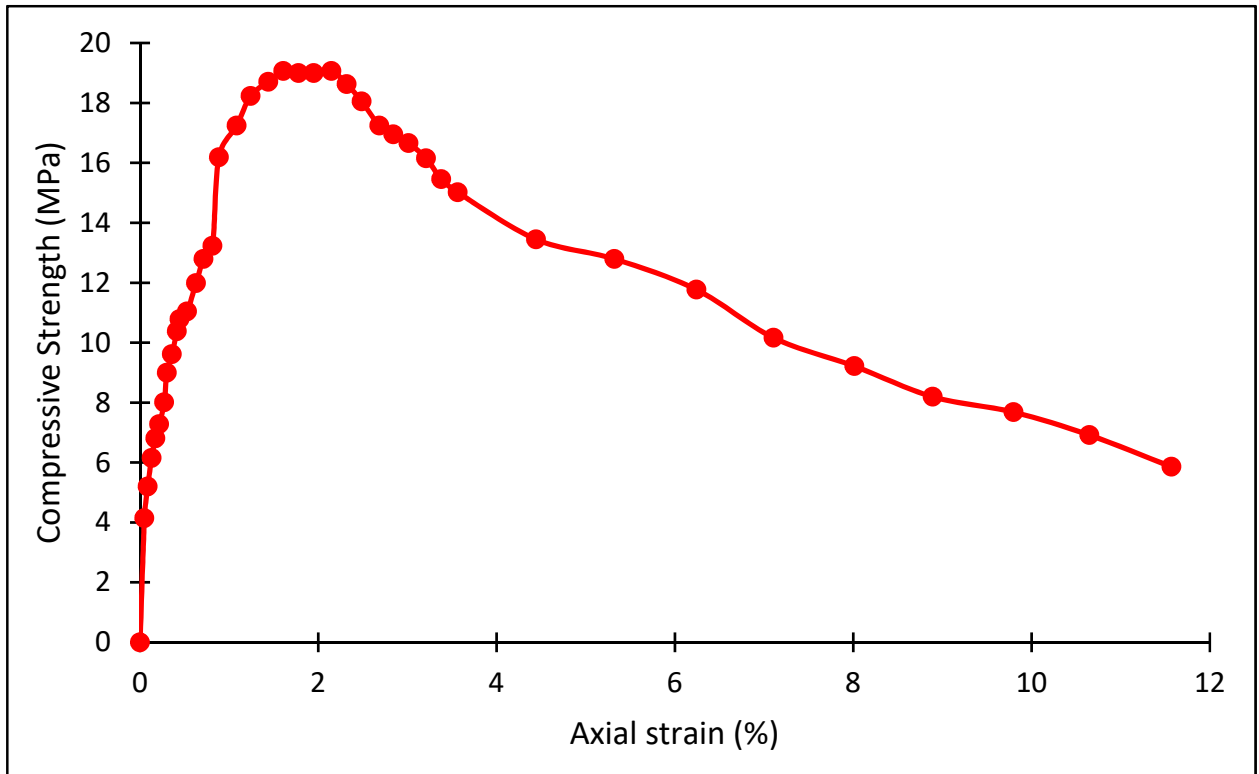

Figure 25. Stress-strain graph for the geopolymer created using Method VII.

\section{Conclusions}

For all the methods, the most important variable in the result was the $\mathrm{NaOH}$ addition procedure, and it was found to be detrimental to first dilute the water with the tailings and then the sodium hydroxide. As observed in the phase diagram of the $\mathrm{NaOH}-\mathrm{H}_{2} \mathrm{O}$ system, it is necessary to dissolve the $\mathrm{NaOH}$ at a temperature higher than $80^{\circ} \mathrm{C}$ to obtain a higher solubility and thus a higher dissolution.

The mineralogical characterization of the tailings is essential to provide an indication of the amount of soluble material that the tailings contain, which is the ultimate source of the aluminosilicate $[20,50-53]$.

From the first methods used for the creation of geopolymers it was concluded that the application of external heat, i.e., the use of an oven during the curing process, is necessary to obtain hardened geopolymers with the copper tailings used with the addition of $\mathrm{NaOH}$. It was also observed that it is necessary to use low quantities of water in the geopolymeric 
mixture to obtain a good consistency and subsequent hardening of the geopolymer. The optimum was found with a water/solids ratio of $20 \%$.

From the different results obtained in Methods VI and VII based on the curing time in the oven at different temperatures, it can be inferred that longer curing times and higher curing temperatures are favorable for the hardening of the sample. After spending time in the oven, the test tubes at $90^{\circ} \mathrm{C}$ demonstrated remarkable hardness in both methods.

The curing temperature is very important in the process of generation of geopolymers based on copper tailings with the addition of $\mathrm{NaOH}$ because copper tailings are known to be less reactive than other sources of aluminosilicates such as fly ash or slag. Thus, when they come into contact with a highly alkaline solution, they dissolve less of the elements important for the occurrence of geopolymerization, such as silicon and aluminum. For this reason it is necessary to apply heat during the curing process, which helps the dissolution of aluminosilicates, and increases the interaction between the source of aluminosilicates and the alkaline solution, thus increasing the reaction speed of geopolymerization, in addition to favoring the hardening of geopolymers [2]. The results shown confirm that working at a temperature of $90^{\circ} \mathrm{C}$ is favorable for hardening.

The $\mathrm{pH}$ values obtained were in the range for a correct dissolution of the aluminosilicates from the copper tailings, which in turn favored the hardening process of the geopolymer [46-49].

The temperature of the mixture during agitation rose to $51.6^{\circ} \mathrm{C}$ due to the dissolution of $\mathrm{NaOH}$ in contact with the water included in the tailings pulp. Because this temperature is not sufficient for the complete dissolution of $\mathrm{NaOH}$, it is deduced that a quantity of this reagent remained without going into solution.

The longer the waiting time after mixing, the higher the yield stress of the geopolymer pastes. Thus, if this mixture needs to be molded or pumped for transfer from one point to another, it should be done immediately after mixing to avoid increasing the rheological properties of the paste.

The obtained mixtures with Methods VI and VII showed high resistance, and achieved good consistency and complete hardening of the specimens.

Author Contributions: H.C. (Hengels Castillo): Writing-review \& editing, Principal investigator, Project administration, Resources, Supervision, Validation; H.C. (Humberto Collado): Writingreview \& editing, Investigation; T.D.: Writing—review \& editing, Investigation; S.S.: Writing—review \& editing, Investigation; M.V.: Resources, Supervision, Validation; P.G.: Resources, Supervision, Project administration; S.P.: Writing-review \& editing, Investigation, Validation, Supervision. All authors have read and agreed to the published version of the manuscript.

Funding: This research received no external funding.

Data Availability Statement: The data presented in this study are available on request from the corresponding author. The data are not publicly available due to the experimental trials have been financed by third parties and there are confidentiality agreements.

Acknowledgments: We are grateful for the support of this research project provided by the Consulting Company JRI Engineering from Chile (https:/ / www.jri.cl/, access on 26 November 2021) and the Center for Research in Sustainable Mining CIMS-JRI (https:/ / www.cimsjri.cl/, access on 26 November 2021).

Conflicts of Interest: Author state no conflict of interest.

\section{References}

1. Wan, Q.; Rao, F.; Song, S.; Zhang, Y. Immobilization forms of ZnO in the solidification/stabilization (S/S) of a zinc mine tailing through geopolymerization. J. Mater. Res. Technol. 2019, 8, 5728-5735. [CrossRef]

2. Tian, X.; Xu, W.; Song, S.; Rao, F.; Xia, L. Effects of curing temperature on the compressive strength and microstructure of copper tailing-based geopolymers. Chemosphere 2020, 253, 126754. [CrossRef] [PubMed]

3. Ahmari, S.; Zhang, L. Production of eco-friendly bricks from copper mine tailings through geopolymerization. Constr. Build. Mater. 2012, 29, 323-331. [CrossRef] 
4. Huang, B.; Feng, Q.; An, D.; Zhang, J. Use of Mine Tailings as Precast Construction Materials through Alkali Activation. Min. Metall. Explor. 2020, 37, 251-265. [CrossRef]

5. Kuranchie, F.A.; Shukla, S.K.; Habibi, D. Utilisation of iron ore mine tailings for the production of geopolymer bricks. Int. J. Min. Reclam. Environ. 2014, 30, 92-114. [CrossRef]

6. Taki, K.; Mukherjee, S.; Patel, A.K.; Kumar, M. Reappraisal review on geopolymer: A new era of aluminosilicate binder for metal immobilization. Environ. Nanotechnol. Monit. Manag. 2020, 14, 100345. [CrossRef]

7. Mu, S.; Liu, J.; Lin, W.; Wang, Y.; Liu, J.; Shi, L.; Jiang, Q. Property and microstructure of aluminosilicate inorganic coating for concrete: Role of water to solid ratio. Constr. Build. Mater. 2017, 148, 846-856. [CrossRef]

8. Farhan, K.Z.; Johari, M.A.M.; Demirboğa, R. Assessment of important parameters involved in the synthesis of geopolymer composites: A review. Constr. Build. Mater. 2020, 264, 120276. [CrossRef]

9. Rifaai, Y.; Yahia, A.; Mostafa, A.; Aggoun, S.; Kadri, E.-H. Rheology of fly ash-based geopolymer: Effect of NaOH concentration. Constr. Build. Mater. 2019, 223, 583-594. [CrossRef]

10. Nadoushan, M.J.; Ramezanianpour, A.A. The effect of type and concentration of activators on flowability and compressive strength of natural pozzolan and slag-based geopolymers. Constr. Build. Mater. 2016, 111, 337-347. [CrossRef]

11. Görhan, G.; Aslaner, R.; Şinik, O. The effect of curing on the properties of metakaolin and fly ash-based geopolymer paste. Compos. Part B Eng. 2016, 97, 329-335. [CrossRef]

12. Nurruddin, M.F.; Haruna, S.; Mohammed, B.S.; Galal, I. Methods of curing geopolymer concrete: A review. Int. J. Adv. Appl. Sci. 2018, 5, 31-36. [CrossRef]

13. Xie, J.; Kayali, O. Effect of initial water content and curing moisture conditions on the development of fly ash-based geopolymers in heat and ambient temperature. Constr. Build. Mater. 2014, 67, 20-28. [CrossRef]

14. Oderji, S.Y.; Chen, B.; Ahmad, M.R.; Shah, S.F.A. Fresh and hardened properties of one-part fly ash-based geopolymer binders cured at room temperature: Effect of slag and alkali activators. J. Clean. Prod. 2019, 225, 1-10. [CrossRef]

15. Krishna, R.; Shaikh, F.; Mishra, J.; Lazorenko, G.; Kasprzhitskii, A. Mine tailings-based geopolymers: Properties, applications and industrial prospects. Ceram. Int. 2021, 47, 17826-17843. [CrossRef]

16. Joseph, D. Geopolymer Chemistry and Applications, 2nd ed.; Institut Geopolymere: Saint Quentin, France, 2008.

17. Zhang, Z.; Provis, J.; Reid, A.; Wang, H. Geopolymer foam concrete: An emerging material for sustainable construction. Constr. Build. Mater. 2014, 56, 113-127. [CrossRef]

18. Shahedan, N.; Abdullah, M.; Mahmed, N.; Kusbiantoro, A.; Tammas-Williams, S.; Li, L.-Y.; Aziz, I.; Vizureanu, P.; Wysłocki, J.; Błoch, K.; et al. Properties of a New Insulation Material Glass Bubble in Geo-Polymer Concrete. Materials 2021, 14, 809. [CrossRef] [PubMed]

19. Lloyd, N.A.; Rangan, B.V. Geopolymer concrete: A review of development and opportunities. In Proceedings of the 35th Conference on Our World in Concrete \& Structures, Singapore, 25-27 August 2010; pp. 25-27. Available online: https: //www.academia.edu/ (accessed on 18 September 2021).

20. Ouffa, N.; Benzaazoua, M.; Belem, T.; Trauchessec, R.; Lecomte, A. Alkaline dissolution potential of aluminosilicate minerals for the geosynthesis of mine paste backfill. Mater. Today Commun. 2020, 24, 101221. [CrossRef]

21. Sun, Q.; Tian, S.; Sun, Q.; Li, B.; Cai, C.; Xia, Y.; Wei, X.; Mu, Q. Preparation and microstructure of fly ash geopolymer paste backfill material. J. Clean. Prod. 2019, 225, 376-390. [CrossRef]

22. Manjarrez, L.; Nikvar-Hassani, A.; Shadnia, R.; Zhang, L. Experimental Study of Geopolymer Binder Synthesized with Copper Mine Tailings and Low-Calcium Copper Slag. J. Mater. Civ. Eng. 2019, 31, 04019156. [CrossRef]

23. Duxson, P.; Provis, J.; Lukey, G.C.; Mallicoat, S.W.; Kriven, W.M.; van Deventer, J.S. Understanding the relationship between geopolymer composition, microstructure and mechanical properties. Colloids Surf. A Physicochem. Eng. Asp. 2005, $269,47-58$. [CrossRef]

24. Samarakoon, M.; Ranjith, P.; Rathnaweera, T.; Perera, S. Recent advances in alkaline cement binders: A review. J. Clean. Prod. 2019, 227, 70-87. [CrossRef]

25. Ahmari, S.; Zhang, L.; Zhang, J. Effects of activator type/concentration and curing temperature on alkali-activated binder based on copper mine tailings. J. Mater. Sci. 2012, 47, 5933-5945. [CrossRef]

26. Bong, S.H.; Xia, M.; Nematollahi, B.; Shi, C. Ambient temperature cured 'just-add-water' geopolymer for 3D concrete printing applications. Cem. Concr. Compos. 2021, 121, 104060. [CrossRef]

27. Al-Mashhadani, M.M.; Canpolat, O. Effect of various $\mathrm{NaOH}$ molarities and various filling materials on the behavior of fly ash based geopolymer composites. Constr. Build. Mater. 2020, 262, 120560. [CrossRef]

28. Hamidi, R.M.; Man, Z.; Azizli, K.A. Concentration of NaOH and the Effect on the Properties of Fly Ash Based Geopolymer. Procedia Eng. 2016, 148, 189-193. [CrossRef]

29. Zhang, D.-W.; Zhao, K.-F.; Xie, F.-Z.; Li, H.; Wang, D.-M. Effect of water-binding ability of amorphous gel on the rheology of geopolymer fresh pastes with the different $\mathrm{NaOH}$ content at the early age. Constr. Build. Mater. 2020, 261, 120529. [CrossRef]

30. Pouhet, R.; Cyr, M.; Bucher, R. Influence of the initial water content in flash calcined metakaolin-based geopolymer. Constr. Build. Mater. 2019, 201, 421-429. [CrossRef]

31. Zahid, M.; Shafiq, N. Effects of Sand/Fly Ash and the Water/Solid Ratio on the Mechanical Properties of Engineered Geopolymer Composite and Mix Design Optimization. Minerals 2020, 10, 333. [CrossRef] 
32. Lahoti, M.; Yang, E.-H.; Tan, K.H. Influence of Mix Design Parameters on Geopolymer Mechanical Properties and Microstructure. Ceram. Eng. Sci. Proc. 2017, 37, 21-33. [CrossRef]

33. Nagral, M.R.; Ostwal, T.; Chitawadagi, M.V. Effect Of Curing Temperature And Curing Hours On The Properties Of Geo-Polymer Concrete. Int. J. Comput. Eng. Res. 2014, 4, 2250-3005.

34. Lahoti, M.; Narang, P.; Tan, K.H.; Yang, E.-H. Mix design factors and strength prediction of metakaolin-based geopolymer Ceram. Int. 2017, 43, 11433-11441. [CrossRef]

35. Reddy, M.S.; Dinakar, P.; Rao, B.H. Mix design development of fly ash and ground granulated blast furnace slag based geopolymer concrete. J. Build. Eng. 2018, 20, 712-722. [CrossRef]

36. Zhang, L.; Ahmari, S.; Zhang, J. Synthesis and characterization of fly ash modified mine tailings-based geopolymers. Constr. Build. Mater. 2011, 25, 3773-3781. [CrossRef]

37. Obenaus-Emler, R.; Falah, M.; Illikainen, M. Assessment of mine tailings as precursors for alkali-activated materials for on-site applications. Constr. Build. Mater. 2020, 246, 118470. [CrossRef]

38. Pouhet, R.; Cyr, M. Carbonation in the pore solution of metakaolin-based geopolymer. Cem. Concr. Res. 2016, 88, 227-235. [CrossRef]

39. Khan, M.; Castel, A.; Noushini, A. Carbonation of a low-calcium fly ash geopolymer concrete. Mag. Concr. Res. 2017, 69, 24-34. [CrossRef]

40. Sun, Z; Vollpracht, A. One year geopolymerisation of sodium silicate activated fly ash and metakaolin geopolymers. Cem. Concr. Compos. 2019, 95, 98-110. [CrossRef]

41. Provis, J.L. Activating solution chemistry for geopolymers. In Geopolymers Structure, Processing, Properties and Industrial Applications; Woodhead Publishing Limited: New Delhi, India, 2009; pp. 50-71. [CrossRef]

42. Provis, J.L.; Rees, C.A. Geopolymer Synthesis Kinetics. In Geopolymers Structure, Processing, Properties and Industrial Applications; Woodhead Publishing Limited: New Delhi, India, 2009; pp. 118-136.

43. Hardjito, D.; Rangan, B.V. Development and properties of low-calcium fly ash-based geopolymer concrete. Res. Rep. GC 2005, 94. Available online: http:/ / www.geopolymer.org/fichiers_pdf/curtin-flyash-GP-concrete-report.pdf (accessed on 18 September 2021).

44. Kong, D.L.Y.; Sanjayan, J.G.; Sagoe-Crentsil, K. Factors affecting the performance of metakaolin geopolymers exposed to elevated temperatures. J. Mater. Sci. 2008, 43, 824-831. [CrossRef]

45. Ahmari, S.; Parameswaran, K.; Zhang, L. Alkali Activation of Copper Mine Tailings and Low-Calcium Flash-Furnace Copper Smelter Slag. J. Mater. Civ. Eng. 2015, 27, 04014193. [CrossRef]

46. Khale, D.; Chaudhary, R. Mechanism of geopolymerization and factors influencing its development: A review. J. Mater. Sci. 2007, 42, 729-746. [CrossRef]

47. Kashani, A.; Provis, J.; Qiao, G.; van Deventer, J.S. The interrelationship between surface chemistry and rheology in alkali activated slag paste. Constr. Build. Mater. 2014, 65, 583-591. [CrossRef]

48. Phair, J.; Van Deventer, J. Effect of silicate activator $\mathrm{pH}$ on the leaching and material characteristics of waste-based inorganic polymers. Miner. Eng. 2001, 14, 289-304. [CrossRef]

49. Gharzouni, A.; Joussein, E.; Samet, B.; Baklouti, S.; Rossignol, S. Effect of the reactivity of alkaline solution and metakaolin on geopolymer formation. J. Non-Cryst. Solids 2015, 410, 127-134. [CrossRef]

50. Keyte, L.M. Fly Ash Glass Chemistry and Inorganic Polymer Cements; Woodhead Publishing Limited: London, UK, 2009.

51. Fernández-Jiménez, A.; Palomo, A. Composition and microstructure of alkali activated fly ash binder: Effect of the activator. Cem. Concr. Res. 2005, 35, 1984-1992. [CrossRef]

52. Fernández-Jiménez, A.; Palomo, A. Nanostructure/microstructure of fly ash geopolymers. Geopolym. Struct. Process. Prop. Ind. Appl. 2009, 89-117. [CrossRef]

53. Murayama, N.; Yamamoto, H.; Shibata, J. Mechanism of zeolite synthesis from coal fly ash by alkali hydrothermal reaction. Int. J. Miner. Process. 2002, 64, 1-17. [CrossRef] 